\title{
Planejamento composicional de Quadrilha, para quarteto de cordas, a partir da Modelagem Sistêmica do Ponteio $n^{\underline{0}} 21$ de Camargo Guarnieri
}

\section{Compositional planning of "Quadrilha", for string quartet, based on the Systemic Modeling of Camargo Guarnieri's "Ponteio no 21"}

\section{Marcel M. Castro-Lima}

Universidade Federal do Estado do Rio de Janeiro (UNIRIO) marcelcastrolima@gmail.com

\section{Liduino Pitombeira}

Universidade Federal do Rio de Janeiro (UFRJ)

pitombeira@musica.ufrj.br

Resumo: Este trabalho apresenta o processo de Modelagem Sistêmica do Ponteio $n^{\underline{0}}$ 21, de Camargo Guarnieri, que deu origem a uma peça para quarteto de cordas intitulada Quadrilha, de Marcel Castro-Lima. O artigo apresenta detalhadamente a análise da obra de Guarnieri e a maneira como o Sistema Composicional resultante dessa análise foi utilizado no Planejamento Composicional da nova obra de Castro-Lima.

Palavras-chave: composição; intertextualidade; análise musical; sistema composicional; modelagem sistêmica.

\begin{abstract}
This work presents the process of Systemic Modeling of Ponteio $n^{\underline{0}} 21$, by Camargo Guarnieri, which gave rise to a piece for string quartet titled Quadrilha, by Marcel Castro-Lima. The article presents in detail the analysis of Guarnieri's work and the way in which the Compositional System resulting from this analysis was used in the Compositional Planning of Castro-Lima's new work.
\end{abstract}

Keywords: composition; intertextuality; musical analysis; compositional system; systemic modeling. 

para quarteto de cordas, a partir da modelagem sistêmica do Ponteio nํ 21 de Camargo Guarnieri. MUSICA THEORICA. Salvador: TeMA, 201807, p. 175-202.

\section{1 - Introdução}

Este artigo trata da realização da composição de Quadrilha a partir da modelagem sistêmica do Ponteio $n^{\underline{0}} 21$ de Camargo Guarnieri. O trabalho está dividido em duas partes. A primeira parte trata da análise do Ponteio $n^{\underline{0}} 21$ através da identificação dos gestos melódicos e da redução desses gestos às suas notas geradoras, simplificando a textura, de maneira que os seus princípios estruturais se tornem mais claros. Na terceira parte iremos propor um modelo de sistema composicional que poderia ter gerado a obra analisada e, a partir desse modelo, planejaremos a nova obra, Quadrilha para quarteto de cordas. É nosso objetivo colaborar com a investigação da linguagem composicional de Camargo Guarnieri no âmbito de seus ponteios, assim como examinar a metodologia da Modelagem Sistêmica em uma perspectiva de geração de repositórios composicionais.

A modelagem sistêmica ${ }^{1}$ é uma metodologia analítica inspirada na técnica homônima utilizada no campo da engenharia e que, na música, se originou a partir de uma convergência da teoria dos sistemas composicionais e da teoria da intertextualidade. Trata-se de uma série de procedimentos através dos quais determinada obra é analisada, com foco em seus princípios estruturais e no comportamento e inter-relação entre seus diversos parâmetros musicais, com o objetivo de se propor um modelo sistêmico, ou sistema composicional, que hipoteticamente a teria gerado. A partir do sistema composicional resultante da análise, é planejada e composta uma nova obra. A obra analisada e a nova obra guardam características intrínsecas em comum sem, no entanto, necessariamente, se aparentarem na superfície. O papel do compositor é determinante tanto durante a modelagem, na escolha dos parâmetros que irão constar no sistema, quanto posteriormente através do planejamento composicional $^{2}$, na escolha de como os parâmetros definidos no sistema irão se comportar.

\footnotetext{
${ }^{1}$ A Modelagem Sistêmica aplicada à composição vem sendo pesquisada por Liduino Pitombeira e seus alunos de graduação e pós-graduação desde 2011. (Moraes, Pitombeira, Lima, Castro-Lima, Mesquita, Oliveira, Silva, Usai, Pascale e Kühn, 2011, 2012, 2013, 2014, 2015, 2016 e 2017). Artigos referentes a essa metodologia podem ser encontrados em <http://ufrj.academia.edu/LiduinoPitombeira $>$. Atualmente, Pitombeira gerencia dois projetos de pesquisa sobre modelagem sistêmica na Escola de Música da Universidade Federal do Rio de Janeiro, como membro do grupo de pesquisas MusMat (<http://musmat.org >).

2 Em nossa metodologia, consideramos que um sistema composicional se articula em níveis musicais profundos, arquetípicos, enquanto os aspectos mais superficiais são tratados em uma fase que denominamos planejamento composicional. Nessa fase de planejamento são decididos aspectos particulares não contemplados pelo sistema composicional, bem como a complementação de materiais associados a parâmetros não declarados no sistema.
} 


\section{2 - Modelagem sistêmica do Ponteio $n^{o} 21$ de Camargo Guarnieri}

O Ponteio $n^{0}$ 21, do terceiro caderno de Camargo Guarnieri, cujos gestos iniciais são mostrados no Exemplo 1, consiste em uma pequena forma ternária $\left(\mathrm{ABA}^{\prime}+\right.$ coda). A primeira seção $(\mathrm{A})$ apresenta ritmo predominantemente contínuo e movimento totalmente espelhado entre as mãos direita e esquerda. A seção intermediária (B) é marcada por um repentino aumento no âmbito, no qual as partes se aproximam dos extremos agudo e grave (subseção b1). Sucessivamente (subseção b2), o âmbito se reduz novamente e surgem interrupções no ritmo intercaladas com os registros extremos anteriores. São observados movimentos intervalares quartais durante essa subseção. A terceira seção $\left(\mathrm{A}^{\prime}\right)$ é uma repetição da primeira seguida de uma coda. Um resumo da macroestrutura da obra é mostrado na Tabela 1 . Nota-se a recorrência exaustiva de um tipo de motivo caracterizado por um movimento melódico de grau conjunto seguido de oitava, da extremidade para o centro. O mesmo movimento é encontrado no Estudo $n^{\underline{o}} 20$ de Guarnieri (Exemplo 2), sobre o qual Marion Verhaalen (2001, p.127) se refere como "figuração de oitava mais uma nota".

A frequência elevada com que esse motivo ocorre no Ponteio $n^{\underline{0}} 21$, nas mãos direita e esquerda de maneira espelhada, levantou a possiblidade de considerar os gestos melódicos recorrentes como unidades. Como consequência da escrita espelhada, todos os movimentos entre as duas vozes são contrários. Apesar disso, não é difícil observar que, considerados os gestos melódicos e não cada nota individualmente, existe uma variedade no tipo de movimentos entre as vozes, como oblíquos e paralelos. Na seção central da peça também podemos observar uma textura mais complexa, considerando-se os gestos melódicos, com a abertura de quatro vozes através do recurso da melodia composta.
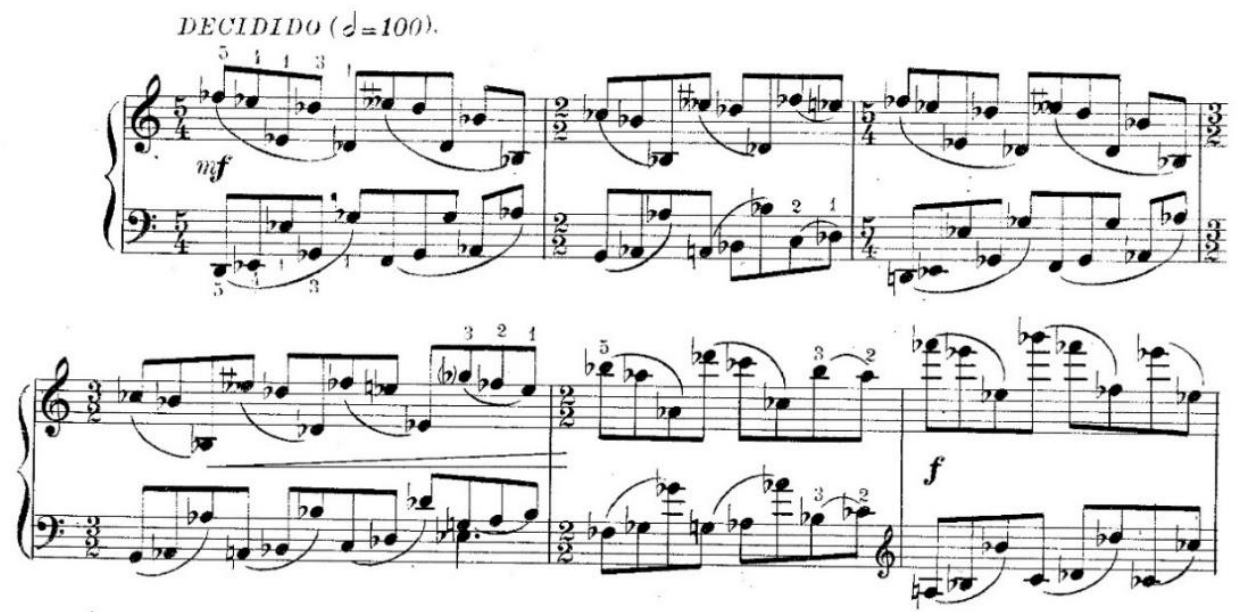

Exemplo 1: Gestos iniciais do Ponteio $n^{\underline{o}} 21$ de Camargo Guarnieri 
Com relação ao material melódico do ponteio, a observação do motivo de oitava mais uma nota também nos forneceu uma solução convincente. $O$ fato de a oitava repetir uma classe de nota, faz com que esta seja reforçada na escuta e se destaque no contexto do ritmo constante e rápido. A nota que antecede, por grau conjunto, a oitava seria então considerada acessória. Assim sendo, nas três últimas colcheias do primeiro compasso da mão direita do Exemplo 2 (grupo de notas indicado com um colchete), a nota Ré é acessória.

\begin{tabular}{|c|c|c|}
\hline Seção & Subseção & Compasso \\
\hline $\mathrm{A}$ & & $01-16$ \\
\hline $\mathrm{B}$ & $\mathrm{b} 1$ & $17-22$ \\
\hline & $\mathrm{b} 2$ & $22-36$ \\
\hline $\mathrm{A}^{\prime}$ & & $37-50$ \\
\hline Coda & & $50-59$ \\
\hline
\end{tabular}

Tabela 1: Macroestrutura do Ponteio $n^{\underline{0}} 21$, de Camargo Guarnieri

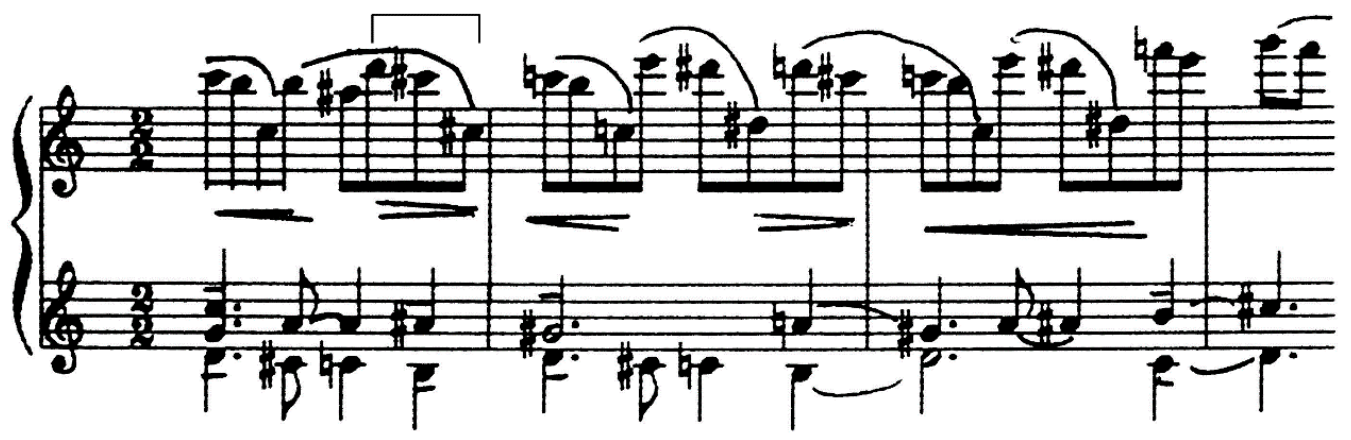

Exemplo 2: Gestos iniciais do Estudo nº 20 de Camargo Guarnieri

Se reduzíssemos esses motivos recorrentes às suas notas mais relevantes em toda a peça, simplificaríamos a textura de tal maneira que seria mais simples observar características como textura, material melódico predominante e tipos de movimento entre as vozes. Logo, a abordagem analítica para este Ponteio será a de uma redução dos motivos às suas alturas geradoras.

Considerando que a configuração motívica formada por esse conjunto de três notas é gerada a partir da nota central, antecedido por grau conjunto e prolongado por oitava, torna-se possível uma redução do gesto melódico à nota central, que chamaremos de nota geradora. Essa configuração motívica pode ser fragmentada em seus componentes constituintes, que também ocorrem separadamente na obra: o movimento de grau conjunto, que denominaremos la1| (para segunda menor) e la2l (para segunda maior), e de oitava, que denominaremos de $|\mathrm{b}|$. Chamaremos então o motivo de oitava mais uma nota de $|\mathrm{a} 1 \mathrm{~b}|$ ou $|\mathrm{a} 2 \mathrm{~b}|$. Para estabelecer qual é a nota acessória e qual é a nota real em 
$|\mathrm{a} 1|$, $|\mathrm{a} 2|$ e em $|\mathrm{b}|$ convencionaremos que em $|\mathrm{a} 1|$ e $|\mathrm{a} 2|$, a primeira nota, antes do grau conjunto, é acessória e a segunda é a nota geradora. Em $|\mathrm{b}|$, a primeira é a nota geradora e a segunda, após o intervalo de oitava, é acessória.

No Exemplo 3 identificamos três configurações motívicas presentes nos primeiros compassos. As notas geradoras foram identificadas segundo as regras estabelecidas (notas com as cabeças brancas). O Exemplo 4 ilustra o resultado da redução, mostrando apenas as notas geradoras do trecho. Observamos, após a redução, que todo o material das notas geradoras do trecho integra a escala pentatônica diatônica ${ }^{3}$ de Solb.

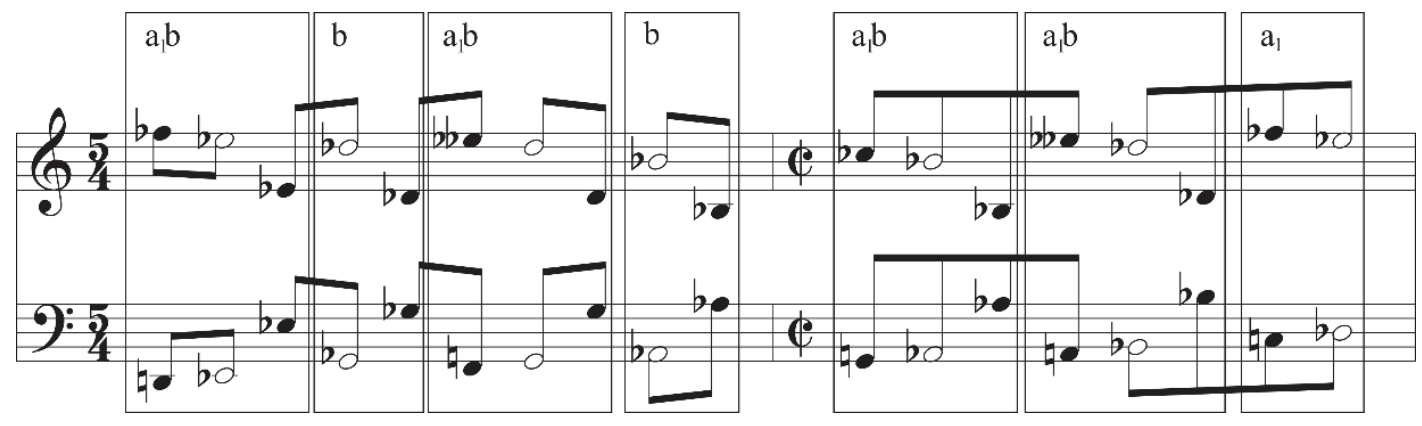

Exemplo 3: Identificação das configurações motívicas a partir da segmentação dos gestos iniciais do Ponteio $n^{\underline{0}} 21$ de Camargo Guarnieri

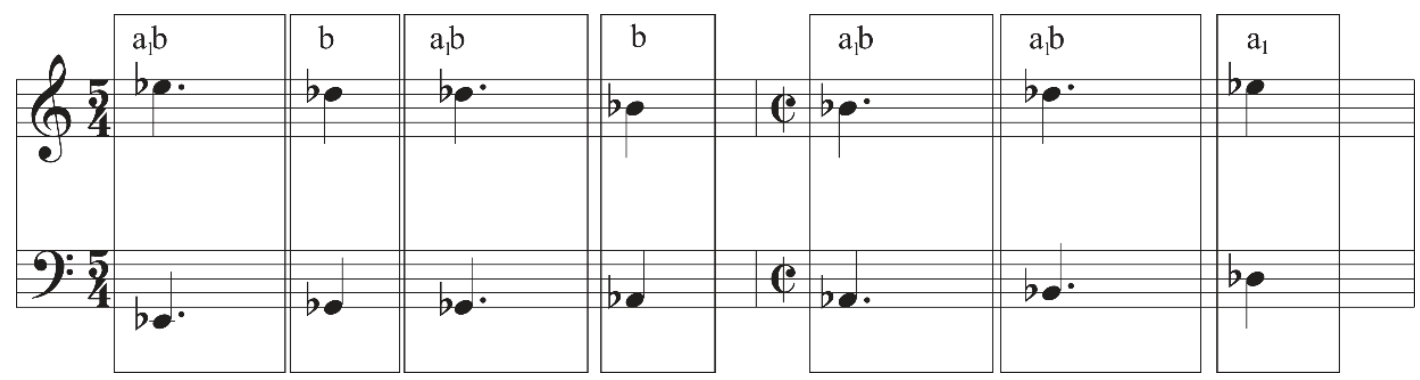

Exemplo 4: Redução das configurações motívicas dos gestos iniciais do Ponteio $n^{\underline{o}} 21$ de Camargo Guarnieri às suas alturas geradoras

Na segunda seção da peça, o intervalo de quarta justa ocorre com frequência, da mesma maneira que as outras configurações encontradas na primeira seção, mostradas anteriormente. Chamaremos esse intervalo de quarta de $\mid \mathrm{cl}$. Para estabelecer a nota geradora e a acessória, utilizaremos a mesma lógica da configuração $|b|$ : a nota geradora é a primeira. Em $|b|$ temos um prolongamento da classe de altura por movimento de oitava. Consideraremos $|\mathrm{c}|$ como uma espécie de prolongamento por quarta justa, já que as notas dessa configuração estão fortemente atreladas umas às outras para compor o

\footnotetext{
${ }^{3}$ Persichetti (1961, p.50) identifica quatro tipos de escala pentatônica: Diatônica, Pelog, Hirajoshi e Kumoi. A pentatônica diatônica corresponde às teclas pretas do piano.
} 
movimento melódico. Esses intervalos de quarta serão considerados também no formato retrógrado, $\mathrm{R}|\mathrm{b}|$ e $\mathrm{R}|\mathrm{c}|$, nos quais a nota geradora é a segunda. $\mathrm{O}$ Exemplo 5 mostra os dois primeiros compassos da seção B e assim como no exemplo anterior, tem destacadas, com a cabeça branca, as notas geradoras. $\mathrm{O}$ Exemplo 6 mostra o resultado da redução, que indica a origem cromática do material. Também é possível observar a textura mais complexa do Exemplo 6, com o destacamento entre as vozes em extremo agudo e grave e a camada interna, resultando na simulação de uma textura a quatro vozes.

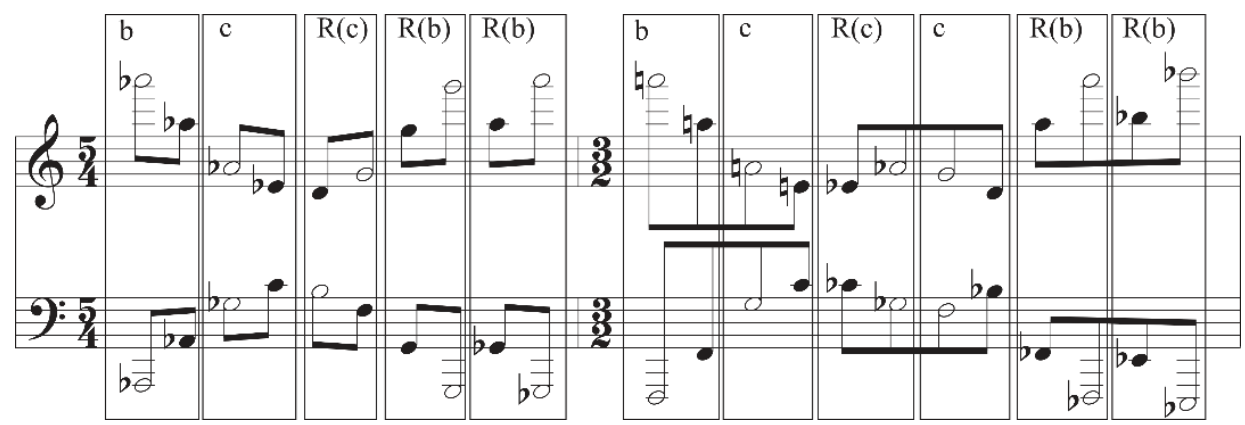

Exemplo 5: Identificação das configurações motívicas a partir da segmentação dos gestos iniciais da segunda seção do Ponteio $n^{-0} 21$ de Camargo Guarnieri

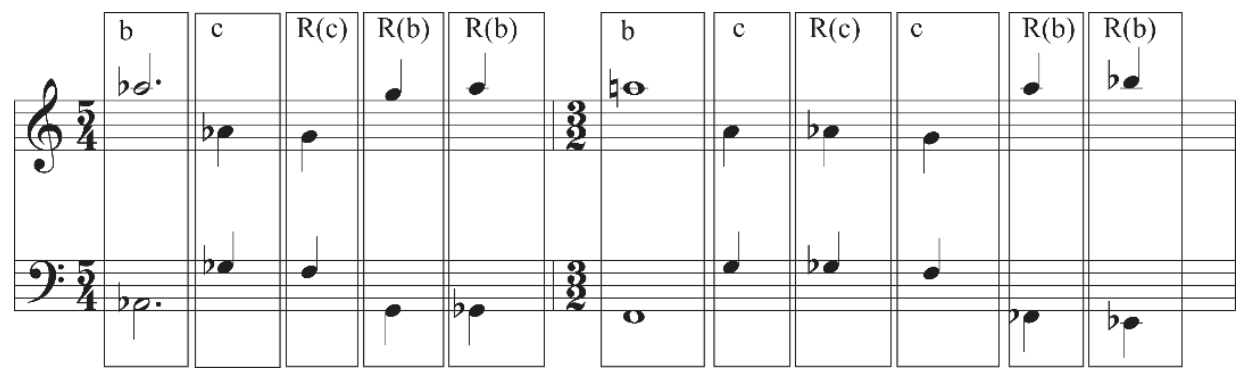

Exemplo 6: Redução das configurações motívicas dos gestos iniciais da segunda seção do Ponteio $n^{\underline{o}} 21$ de Camargo Guarnieri às suas alturas geradoras

Uma análise prospectiva da obra nos revela que toda a sua estrutura gestual pode ser compreendida através dessas estruturas motívicas e suas transformações (inversões, retrogradações e rotações) e justaposições. Ao longo da peça, identificamos também duas configurações com baixa taxa de ocorrência: $|d|$, intervalo de quinta justa justaposto a um intervalo de quarta justa e lel, intervalo de terça maior. Essas são as únicas exceções aos motivos formados pela combinação de $|a|,|b|$, e $|c|$.

Fizemos um levantamento de todas as configurações motívicas presentes no Ponteio $n^{\underline{0}}$ 21, derivadas dos cinco motivos básicos $|\mathrm{a}|,|\mathrm{b}|,|\mathrm{c}|,|\mathrm{d}|$, e $|\mathrm{e}|$. O apêndice mostra a análise na integra, com as configurações identificadas acima dos gestos melódicos. Levando em conta que, devido à escrita especular, a maioria das configurações motívicas presentes na mão direita correspondem ao 
inverso na mão esquerda, decidimos, para atingir uma apresentação visualmente mais limpa, indicar somente as configurações da mão direita a não ser quando, excepcionalmente, a mão esquerda apresenta uma configuração diferente. Logo, onde só houver a identificação da configuração motívica da parte superior, pressupõem-se que a parte inferior corresponde ao exato inverso, ou seja, a mesma configuração invertida. Por exemplo, onde houver apenas $|\mathrm{b}|$ indicado na parte superior, a parte inferior corresponde a um $|\mathrm{b}|$ invertido (duas primeiras colcheias do Exemplo 7). Onde a parte inferior não apresentar a mesma configuração, ocorrem dois tipos de diferenciação. No primeiro caso cabe apenas às configurações motívicas que contenham em si o motivo básico la l, que como já observamos pode variar de índice (1 ou 2) de acordo com a qualidade do intervalo de segunda (menor ou maior, respectivamente). Onde apenas o índice diferir, ou seja, se o intervalo de $|a|$ for de segunda maior na parte superior e menor na parte inferior, a configuração da parte inferior vai estar destacada, pressupondo sua inversão. No Exemplo 7, a terceira, quarta e quinta colcheias são indicadas na parte superior por $|a 2 b|$ e por $|a 1 b|$ na parte inferior. $O$ segundo caso compreende os poucos momentos em que a configuração na mão direita é diferente da configuração motívica da mão esquerda. No Exemplo 7, as três últimas colcheias, por exemplo, são indicadas na parte superior por $|R(a 2) b|$ e por $|R(a 2 b)|$ na parte inferior. Nesse caso, para tornar essas exceções mais visíveis, adicionamos um retângulo sombreado sobrepondo-as.

Com o objetivo de construir o nosso modelo (sistema composicional), para cada configuração motívica, atribuímos uma descrição formal que demonstra uma operação pela qual a nota geradora se transforma no gesto melódico correspondente. A Tabela 2 ilustra os seis motivos básicos exemplificados musicalmente com as notas geradoras destacadas em branco, suas descrições formais e a taxa de ocorrência na forma original (mão direita) e na forma invertida (mão esquerda) das configurações básicas isoladas (sem estarem combinadas com outras). Repare que a configuração le l não ocorre nenhuma vez isoladamente. Sua única aparição é na mão esquerda dentro da configuração la1cel.

A partir do modelo formal, podemos aplicar qualquer configuração motívica a uma nota qualquer (n), onde temos que Tx(y) significa transposição em x semitons da altura y e que || significa justaposição. Por exemplo, se aplicamos $|a 1|$, com descrição formal T1(n) || n, a uma determinada nota n, teremos sua transposição um semitom acima justaposta à própria nota n. $\mathrm{O}$ resultado dessa aplicação à nota Dó $4{ }^{4}$ está exemplificado na segunda coluna da Tabela 2. Na configuração $|\mathrm{b}|$ temos que $|\mathrm{b}|=\mathrm{n}|| \mathrm{T}-12(\mathrm{n})$, ou seja, a própria nota justaposta à sua transposição doze semitons abaixo (oitava justa).

\footnotetext{
${ }^{4}$ Neste trabalho consideraremos o Dó3 como o dó central.
} 


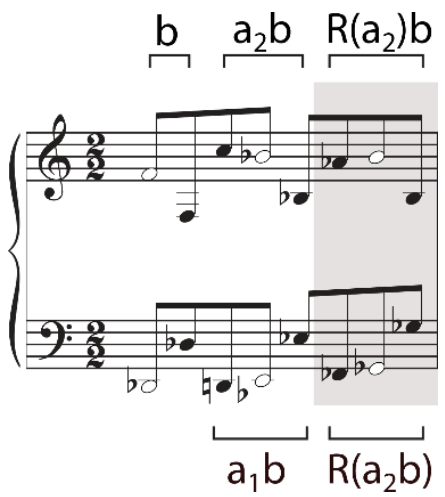

Exemplo 6: Identificação das diferenças entre mão direita e mão esquerda nas nomenclaturas das configurações motívicas dos gestos do Ponteio $n^{\circ} 21$ de Guarnieri

\begin{tabular}{|c|c|c|c|c|c|c|}
\hline Rótulo & Configuração & Modelo formal & Ocorrências & $\%$ & $\begin{array}{c}\text { Ocorrências } \\
\text { do Inverso }\end{array}$ & $\begin{array}{c}\% \\
1\end{array}$ \\
\hline$a_{1}$ & $g^{b-0}$ & $\mathrm{~T}_{1}(\mathrm{n}) \| \mathrm{n}$ & 4 & 1,08 & 8 & 2,16 \\
\hline$a_{2}$ & $6=0$ & $T_{2}(n) \| n$ & 4 & 1,08 & 0 & 0,00 \\
\hline b & $6 \sqrt{0}$ & $n \| T_{-12}(n)$ & 42 & 11,29 & 41 & 22,04 \\
\hline c & $e^{\circ} \cdot$ & $n \| T_{-5}(n)$ & 14 & 2,86 & 21 & 11,29 \\
\hline d & $6 \sqrt{6 \cdot \cdot \cdot}$ & $n\left\|T_{-7}(n)\right\| T_{-12}(n)$ & 1 & 0,27 & 1 & 0,27 \\
\hline e & $g_{0}^{0}$ & $n \| T_{-4}(n)$ & 0 & 0 & 0 & 0 \\
\hline
\end{tabular}

Tabela 2: Configurações motívicas básicas com descrição formal e taxa de ocorrência

As Tabelas 3 e 4 mostram as configurações motívicas mais complexas, formadas a partir da combinação das configurações básicas, assim como suas inversões, retrogradações ou rotações, que estão presentes no Ponteio $n^{\underline{o}} 21$. Reduzindo todas as configurações às suas notas geradoras chegamos a uma escrita a duas vozes, que na seção da peça central se estende a quatro vozes pelo recurso da melodia composta.

Chegamos a um sistema composicional no qual, a partir de um trecho précomposto, aplicam-se configurações motívicas a cada nota, de maneira especular entre as vozes, ou seja, o movimento observado na voz superior deverá ocorrer de maneira inversa na voz inferior. Esse sistema composicional hipotético teria o potencial de, em pelo menos uma de suas aplicações, gerar a obra original analisada. Em outras palavras, se partíssemos do coral oriundo da redução do 
Ponteio $n^{0} 21$ de Guarnieri e aplicássemos configurações motívicas coincidentes com as observadas no Ponteio $n^{0}$ 21, na mesma ordem e mesmo ritmo, para compor uma obra para piano, com o andamento coincidente com o do Ponteio $n^{\underline{0}}$ 21 reconstruiríamos o próprio ponteio.

\begin{tabular}{|c|c|c|c|c|c|c|}
\hline Rótulo & Configuração & Modelo formal & 0 & $\%$ & 1 & $\%$ \\
\hline$a_{1} b$ & $g^{\circ \cdot 0}$ & $T_{1}(n)\|n\| T_{-12}(n)$ & 46 & 24,73 & 60 & 32,26 \\
\hline$a_{2} b$ & $6 \cdot 0$ & $T_{2}(n)\|n\| T_{-12}(n)$ & 14 & 7,53 & 4 & 2,15 \\
\hline$R\left(a_{1} b\right)$ & b. & $\mathrm{T}-12(\mathrm{n})\|\mathrm{n}\| \mathrm{T} 1(\mathrm{n})$ & 2 & 1,07 & 3 & 1,61 \\
\hline $\mathrm{R}\left(\mathrm{a}_{2} \mathrm{~b}\right)$ & b. & $T-12(n)\|n\| T 2(n)$ & 1 & 0,54 & 0 & 0,00 \\
\hline$a_{2} a_{1}$ & $g^{b-b e c}$ & $T_{2}\left(T_{1}(n)\right)\left\|T_{1}(n)\right\| n$ & 2 & 1,07 & 0 & 0,00 \\
\hline$a_{1} a_{2}$ & $b^{b-h_{0}}$ & $T_{1}\left(T_{2}(n)\right)\left\|T_{2}(n)\right\| n$ & 0 & 0,00 & 2 & 1,07 \\
\hline $\mathrm{I}\left(\mathrm{a}_{2}\right) \mathrm{b}$ & $g_{0}$ & $\mathrm{~T}_{-2}(\mathrm{n})\|n\| \mathrm{T}_{-12}(\mathrm{n})$ & 4 & 0,27 & 0 & 0,00 \\
\hline $\mathrm{ROT}_{2} \mathrm{R}\left(\mathrm{a}_{1}\right) \mathrm{b}$ & b. & $\mathrm{T}_{-12}(\mathrm{n})\left\|\mathrm{T}_{-1}(\mathrm{n})\right\| \mathrm{n}$ & 1 & 0,54 & 1 & 0,54 \\
\hline$a_{1} c c$ & $b^{b \cdot c \cdot c}$ & $T_{1}(n)\|n\| T_{-5}(n) \| T_{-5}\left(T_{-5}-(n)\right)$ & 2 & 1,07 & 0 & 0,00 \\
\hline$a_{1} c e$ & $b^{b \cdot 0 \cdot 0} \cdot$ & $T_{1}(n)\|n\| T-5(n) \| T-4(T-5(n))$ & 0 & 0,00 & 1 & 0,54 \\
\hline
\end{tabular}

Tabela 3: Configurações motívicas derivadas com descrição formal e taxa de ocorrência

Esse sistema composicional oferece diversas possibilidades de utilização, que podem se aproximar ou se afastar do Ponteio $n^{\underline{0}} 21$ com relação à semelhança entre este e as possíveis obras geradas pelo sistema. Elaboramos a Tabela 4 que mostra as 16 possibilidades de utilização com relação à manutenção ou diferenciação de 4 parâmetros/materiais em comparação com o ponteio de Guarnieri. ${ }^{5}$ A letra $G$ significa que o parâmetro ou o material foi mantido

\footnotetext{
${ }^{5}$ A quantidade de possibilidades é uma função exponencial de base 2 da quantidade de parâmetros considerados. Assim, se considerarmos cinco parâmetros, por exemplo o número de possibilidades se eleva para $32\left(=2^{5}\right)$.
} 
conforme o Ponteio $n^{-} 21$ e a letra $N$ significa que houve modificação e aplicação de um novo tratamento.

\begin{tabular}{|c|c|c|c|c|c|c|}
\hline Rótulo & Configuração & Modelo formal & & $\%$ & & $\%$ \\
\hline$R(b)$ & b. & $T_{-12}(n) \| n$ & 16 & 8,60 & 16 & 8,60 \\
\hline$R(c)$ & $6 \cdot 5$ & $T_{-5}(n) \| n$ & 3 & 1,61 & 34 & 1,61 \\
\hline $\mathrm{cc}$ & $\frac{b}{2 \cdot .}$ & $n++T_{-5}(n) \| T_{-5}\left(T_{-5}(n)\right)$ & 6 & 3,23 & 6 & 3,23 \\
\hline $\mathrm{R}(\mathrm{cc})$ & 6.5 & $T_{-5}\left(T_{-5}(n)\right) \| T-5(n)++n$ & 11 & 5,91 & 11 & 5,91 \\
\hline$c^{*} c$ & 6. & $\mathrm{n} / / \mathrm{T}_{-5}(\mathrm{n})|| \mathrm{T}_{-5}\left(\mathrm{~T}_{-5}(\mathrm{n})\right)$ & 6 & 3,23 & 0 & 0,00 \\
\hline$c c^{*}$ & b: & $\mathrm{n} / / \mathrm{T}_{-5}(\mathrm{n}) / / \mathrm{T}_{-5}\left(\mathrm{~T}_{-5}(\mathrm{n})\right)$ & 5 & 2,69 & 5 & 2,69 \\
\hline$n++R(c c)$ & $b \sqrt{b} \cdot$ & $n\left\|T_{-5}\left(T_{-5}(n)\right)\right\| T-5(n) \| n$ & 1 & 0,54 & 1 & 0,54 \\
\hline$n++R(c))(b)$ & $\oint^{\circ} \cdot \cdots$ & $n\left\|T_{-5}\left(T_{-5}(n)\right)\right\| T-5(n)\|n\| T_{12}(n)$ & 1 & 0,54 & 1 & 0,54 \\
\hline$a_{1}$ be & $b^{b \cdot d} \cdot b$ & 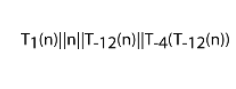 & 0 & 0,00 & 1 & 0,54 \\
\hline
\end{tabular}

Tabela 4: Configurações motívicas derivadas com descrição formal e taxa de ocorrência

O ritmo em Guarnieri é constante, com interrupções breves na segunda seção, mas todas os gestos melódicos são formados por colcheias. Se utilizarmos as configurações motívicas para construir os gestos melódicos com ritmo variado, estaremos nos diferenciando. As configurações motívicas básicas $|\mathrm{a}|,|\mathrm{b}|,|\mathrm{c}|$, $|d|$, e $\mid$ el, podem ser utilizadas para formar as configurações motívicas como exemplificado nas Tabelas 2, 3 e 4, ou novas combinações aproximando a nova obra com a de Guarnieri. Do contrário, as cinco configurações básicas podem ser modificadas conforme a vontade do compositor, resultando em um distanciamento. A escrita especular está presente em todo o Ponteio $n^{\underline{0}} 21$, mas se considerarmos a possibilidade de não aplicar as configurações motívicas de maneira especular estaríamos nos afastando do intertexto. Outra possibilidade que levaria à diferenciação seria a de utilizar partes livres sem a aplicação de configurações motívicas.

Organizamos os parâmetros na Tabela 5 do mais superficial ao mais profundo, sendo o mais superficial o mais perceptível na audição, resultando na ordem: Ritmo, Escrita Especular, Configurações Básicas e Parte Livre. Assim, 
temos em 1 a maior aproximação possível com o Ponteio $n^{\underline{0}}$ 21, e em 16 a menor possível.

\begin{tabular}{|c|c|c|c|c|}
\hline Seções & Ritmo & Escrita especular & Configurações básicas & Parte livre \\
\hline I & G & G & G & G \\
\hline 2 & G & G & G & N \\
\hline 3 & G & G & N & G \\
\hline 4 & G & G & N & N \\
\hline 5 & G & N & G & G \\
\hline 6 & G & N & G & N \\
\hline 7 & G & N & N & G \\
\hline 8 & G & N & G & N \\
\hline 9 & N & G & G & G \\
\hline I0 & N & G & N & G \\
\hline II & N & G & N & N \\
\hline I2 & N & G & G & G \\
\hline I3 & N & N & G & N \\
\hline I4 & N & N & N & G \\
\hline I5 & N & N & & N \\
\hline I6 & N & N & & \\
\hline
\end{tabular}

Tabela 5: Os dezesseis níveis de diferenciação resultantes das possibilidades de combinações dos parâmetros e materiais com relação ao Ponteio $n^{0} 21$ de Guarnieri

Com relação ao trecho pré-composto, poderíamos manter o coral resultante da redução do ponteio de Guarnieri ou compor um novo a ser utilizado. Manter o coral do Ponteio $n^{\underline{0}} 21$ não significa, assim como para nenhum outro dos quatro aspectos, estabelecer um alto grau de semelhança entre as obras. Se utilizarmos o coral do Ponteio $n^{\underline{0}} 21$, mas modificarmos as configurações básicas e sua ordem, e usarmos o ritmo livremente, o resultado será bastante distinto.

O nível de diferenciação não precisa ser necessariamente fixo durante o planejamento composicional da nova obra. Desta forma, é possível utilizar diferentes níveis para diferentes seções de uma mesma peça. Em Quadrilha, utilizamos diversos níveis de diferenciação para as diversas seções da obra. A escolha do nível de diferenciação já se configura como um fator composicionalmente interessante, uma vez que se pode propositadamente afastar-se ou aproximar-se do intertexto.

O exemplo da Tabela 6 mostra uma proposta de planejamento formal hipotético baseado nos níveis de diferenciação onde a cada seção é atribuído um nível. A Figura 1 representa, através das seções, o distanciamento entre a obra nova e o Ponteio $n^{\underline{0}} 21$ de acordo com os parâmetros propostos na Tabela 5.

\begin{tabular}{|c|c|c|c|c|c|c|}
\hline Seção & A & B & C & D & E & A $^{\prime}$ \\
\hline Nível & 4 & 8 & 16 & 14 & 0 & 4 \\
\hline
\end{tabular}

Tabela 6: Planejamento formal a partir dos níveis de diferenciação 


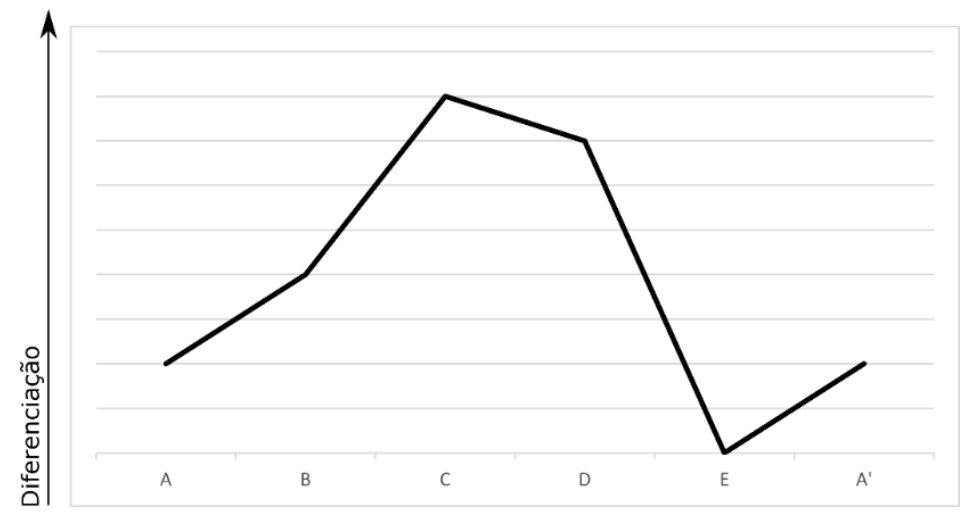

Figura 1: Gráfico representando o nível de diferenciação através das seções de acordo com o planejamento hipotético mostrado na Tabela 6

\section{3 - Sistema Composicional do Ponteio no 21}

Definição 1: Deve ser pré-composto um trecho homofônico (ou reaproveitado o oriundo da redução do Ponteio $n^{0}$ 21) ao qual serão aplicadas configurações motívicas derivadas das configurações básicas utilizadas por Guarnieri (Tabela 5) ou criadas pelo compositor.

Definição 2: A aplicação das configurações motívicas deve se dar predominantemente de maneira especular, ou seja, nas vozes consideradas inferiores, as configurações atuam de maneira inversa, com relação às vozes superiores.

Definição 3: A maneira como o sistema é utilizado pode ser manipulada de forma que o grau de diferenciação entre a obra modelada e a nova obra varia no decorrer desta. Aspectos como a escolha das configurações motívicas, a aplicação especular ou não destas, a presença de partes livres, sem aplicação de configurações motívicas, a utilização ou não do mesmo trecho homofônico do Ponteio $n^{-} 21$ e a possível semelhança rítmica com este (ritmo constante), podem influenciar o referido grau de diferenciação.

\section{4 - Planejamento Composicional de Quadrilha}

Quadrilha, foi composta em 2015 a partir da modelagem sistêmica do Ponteio $n^{\underline{0}} 21$ de Camargo Guarnieri. Cada seção corresponde a uma maneira diferente de utilização do sistema, com relação ao grau de semelhança entre a nova obra e o Ponteio $n^{-} 21$. De maneira geral, em Quadrilha, a seção A tem o maior grau de semelhança com relação ao Ponteio $n^{\underline{0}} 21$, seguido de B, enquanto C 
apresenta um alto grau de diferenciação. A Tabela 7, indica a variação no grau de semelhança, ilustrado também na Figura 2. Essa tabela foi enriquecida, para efeitos comparativos, com fatores quantitativos resultantes de pesos atribuídos aos parâmetros. Como se trata de um sistema de base 2, obteremos uma clara diferenciação se os pesos forem extraídos de uma progressão geométrica com razão $2(1,2,4,8 \ldots)$. Classificamos os parâmetros por ordem de importância na percepção para atribuir-lhes pesos. Assim, o ritmo ganha o maior peso (8), seguido da escrita especular (4), configurações motívicas (2) e, por último, parte livre (1).

No que diz respeito à nova instrumentação, duas observações se mostram pertinentes com relação à natureza do modelo de sistema composicional obtido a partir do Ponteio $n^{\underline{0}} 21$, para piano. Primeiramente, o Ponteio $n^{2} 21$ está composto principalmente a duas vozes. Para o quarteto de cordas, iremos compor um esqueleto a quatro vozes, o que permite que tenhamos possibilidades mais variadas no que diz respeito à escrita especular. Em termos exaustivos, temos uma gama de dez possibilidades de distribuição especular, divididas em três grupos, se considerarmos três tipos de divisão das vozes: (1) um eixo dividindo dois grupos de duas vozes (Figura 3); (2) dois eixos dividindo as quatro vozes de duas em duas (Figura 4); (3) um eixo dividindo cada voz das outras três (Figura 5). Todas as formas de tratamento da escrita especular utilizadas em Quadrilha estão organizadas por seção na Figura 6. Nessa figura, observamos que nas seções c1 e c3 não utilizamos escrita especular.

\begin{tabular}{|c|c|c|c|c|c|}
\hline Seções & Ritmo (8) & Escrita Especular(4) & Configurações básicas (2) & Parte livre (1) & Resultado \\
\hline a1 & G & G & G & G & 15 \\
\hline a2 & G & G & G & N & 14 \\
\hline b1 & N & G & N & G & 5 \\
\hline b2 & N & G & G & G & 7 \\
\hline a1 & G & G & G & N & 15 \\
\hline c1 & N & N & N & G & 7 \\
\hline c2 & N & G & G & G & 1 \\
\hline c3 & N & N & N & G & 5 \\
\hline c4 & N & G & N & 13 \\
\hline a3 & G & G & N &
\end{tabular}

Tabela 7: Semelhança ou diferenciação entre a nova obra e o Ponteio $n^{\underline{0}} 21$.

N significa que o parâmetro recebeu um novo tratamento;

$\mathrm{G}$ significa que foi utilizado de forma similar à peça de Guarnieri 

para quarteto de cordas, a partir da modelagem sistêmica do Ponteio no 21 de Camargo Guarnieri. MUSICA THEORICA. Salvador: TeMA, 201807, p. 175-202.

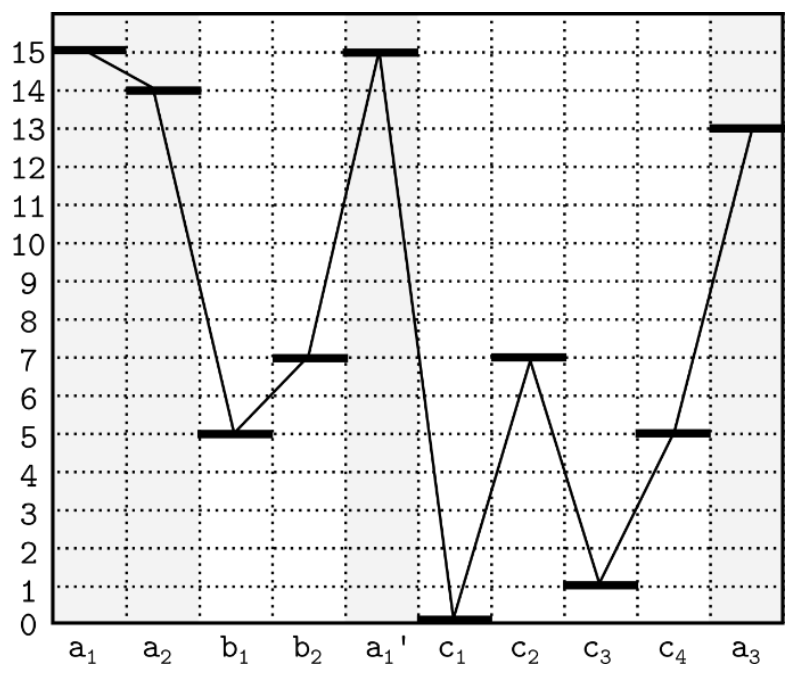

Figura 2: Gráfico do grau de semelhança entre a nova obra e o Ponteio $n^{\underline{o}} 21$ de acordo com as seções

A segunda observação diz respeito ao prolongamento de oitava. Notas repetidas no piano em alta velocidade não é idiomático. É comum o uso de oitava quando se quer repetir uma classe de altura rapidamente. Já em instrumentos de corda, repetição de nota é um procedimento comum e idiomático (Wagner 1959, p. 63). Esse fato nos leva a considerar o motivo de prolongamento por oitava, ou seja, o motivo $|\mathrm{b}|$, como um motivo por prolongamento da classe de nota, podendo utilizá-lo com liberdade na nova obra para quarteto de cordas, na forma de nota repetida. A estrutura formal de Quadrilha está apresentada na Tabela 8. A maneira como o sistema foi utilizado em cada pequena seção será comentada a seguir.

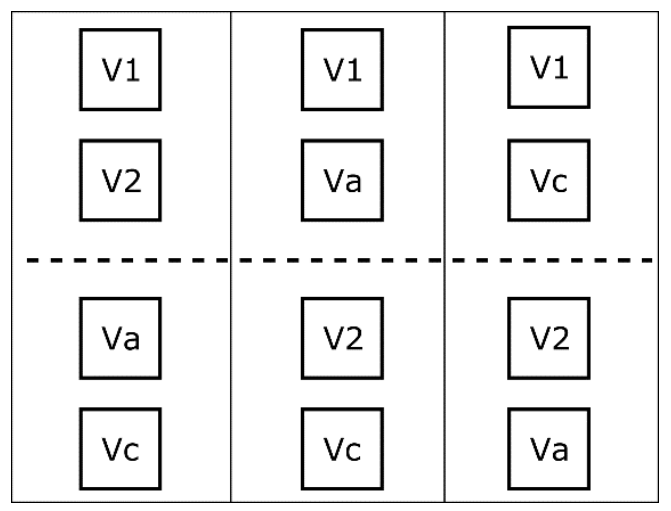

Figura 3: Um eixo dividindo dois grupos de duas vozes 


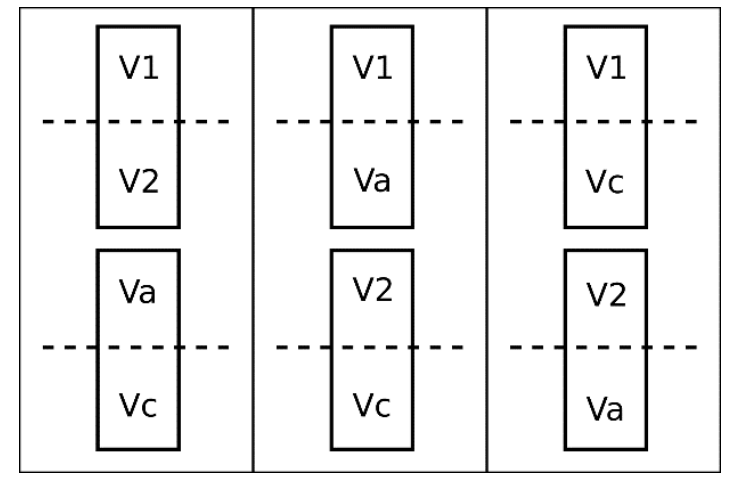

Figura 4: Seis eixos dividindo as quatro vozes de duas em duas

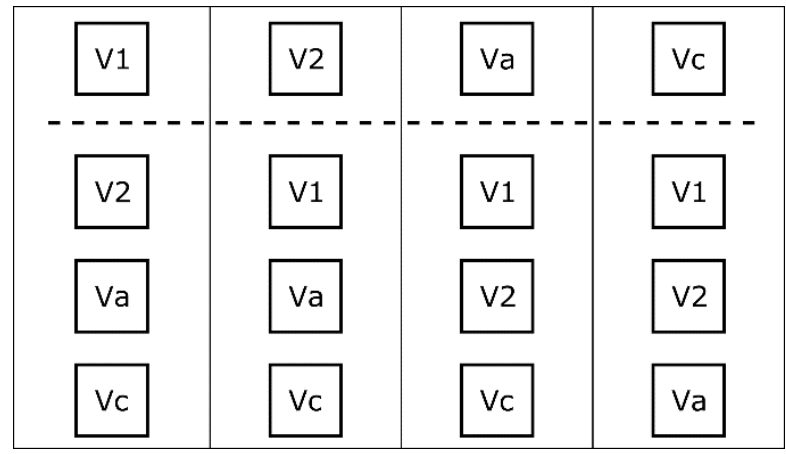

Figura 5: Um eixo dividindo cada voz das outras três

O Exemplo 7 demonstra a utilização do sistema na seção a1. Na parte superior, observamos o esqueleto homofônico pré-composto e as configurações motívicas aplicadas a cada nota de maneira especular entre as duas vozes superiores e as duas vozes inferiores. Abaixo, podemos observar o resultado da aplicação das configurações motívicas, observando a opção anteriormente mencionada de utilizar a configuração $|\mathrm{b}|$ como repetição de classe de nota. A forma de utilização do sistema apresentada nesse trecho possui o maior grau de similaridade com o Ponteio $n^{\underline{o}} 21$ de Guarnieri, pois utiliza as mesmas configurações básicas encontradas neste: ritmo constante e escrita especular. 


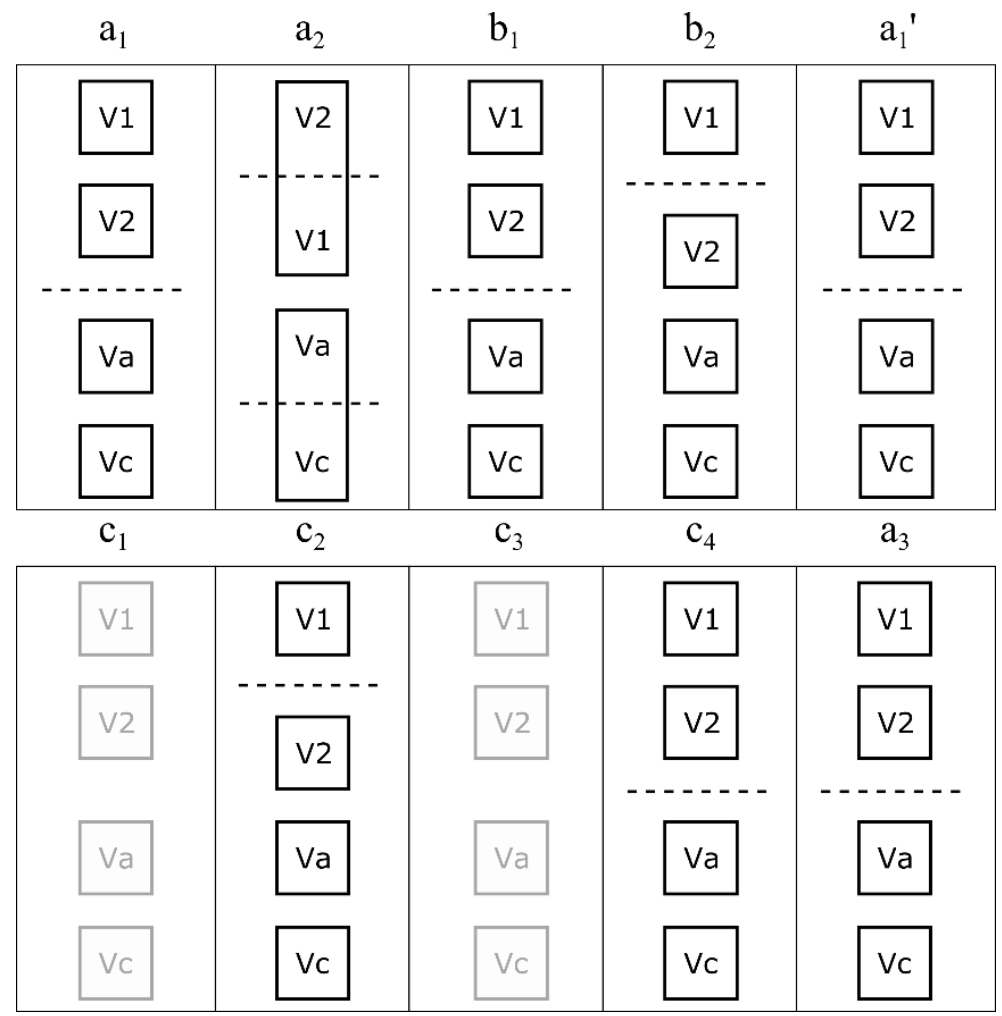

Figura 6: Esquema de utilização das possibilidades de uso do eixo especular por seções em Quadrilha

\begin{tabular}{|c|c|c|c|c|c|c|c|c|c|}
\hline A & & B & & $\mathrm{A}^{\prime}$ & C & & & & $\mathrm{A}^{\prime}$ \\
\hline a1 & $\mathrm{a} 2$ & b1 & b2 & a1 & c1 & c2 & c3 & c4 & a3 \\
\hline
\end{tabular}

Tabela 8: Estrutura formal de Quadrilha

No Exemplo 8, podemos observar uma nova possibilidade de utilização do sistema, agora na seção a2. Temos, na parte superior desse exemplo, o esqueleto homofônico com uma escrita a duas vozes, que correspondem na peça a viola e violoncelo, com o eixo especular entre elas. Na parte inferior do exemplo, mostramos o resultado da aplicação das configurações motívicas e uma parte composta livremente para violinos. Utilizamos também nesse trecho a possibilidade de não aplicar às notas do esqueleto nenhuma configuração motívica, como pode ser observado no último compasso. A opção por não aplicar nenhuma configuração será identificada pelo caractere $|0|$. A utilização da parte livre e da nota do esqueleto sem configuração motívica aplicada aumenta a diferenciação com relação ao Ponteio $n^{\underline{0}} 21 \mathrm{em}$ a2 se comparada a a1. As configurações, a escrita especular e o ritmo, porém, continuam similares aos do Ponteio $n^{\underline{o}} 21$. 

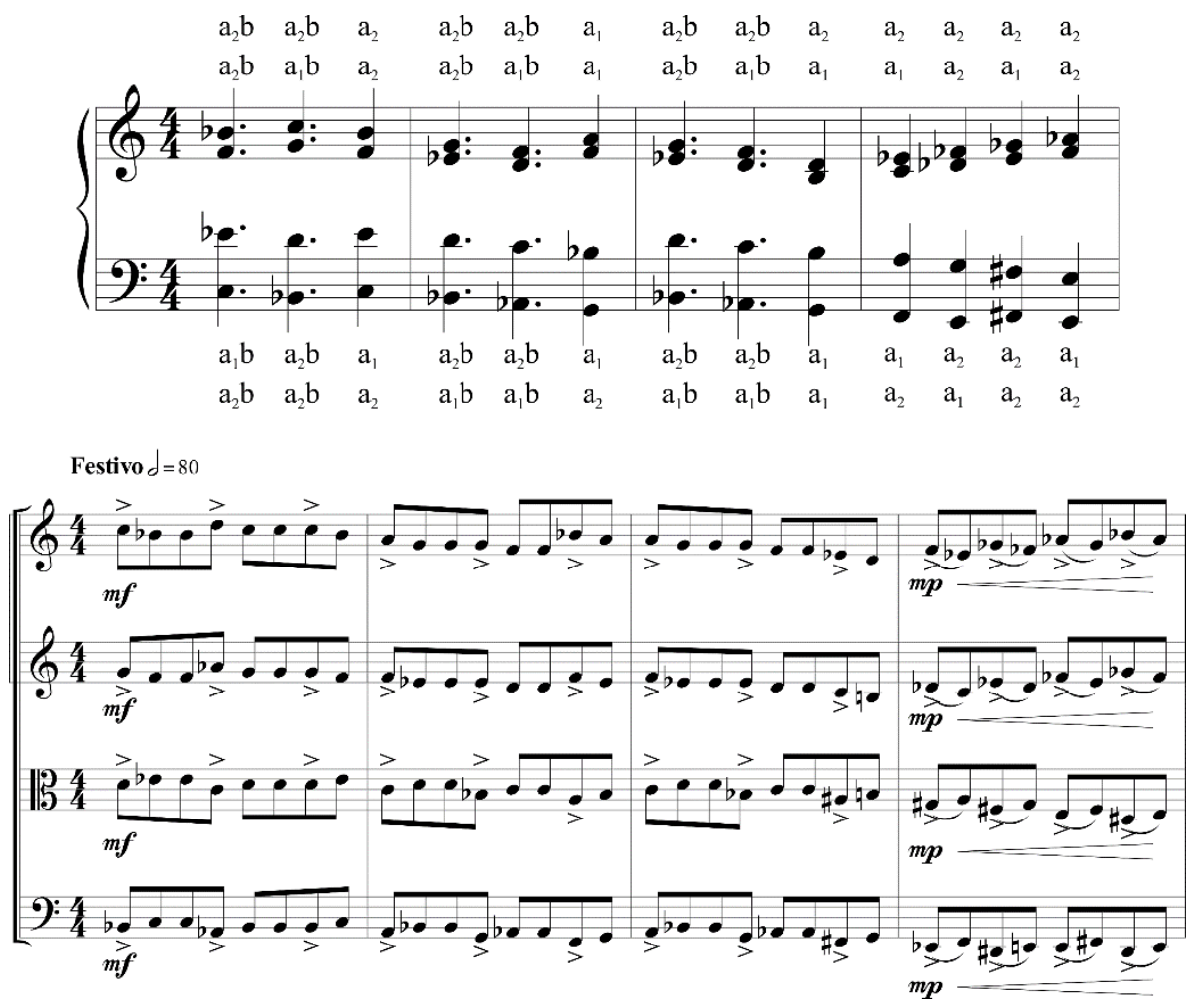

Exemplo 7: Aplicação das configurações motívicas em a1. Acima o esqueleto homofônico com configurações motívicas aplicadas e abaixo resultado da realização a quatro vozes com escrita especular entre as duas vozes superiores e as duas inferiores.
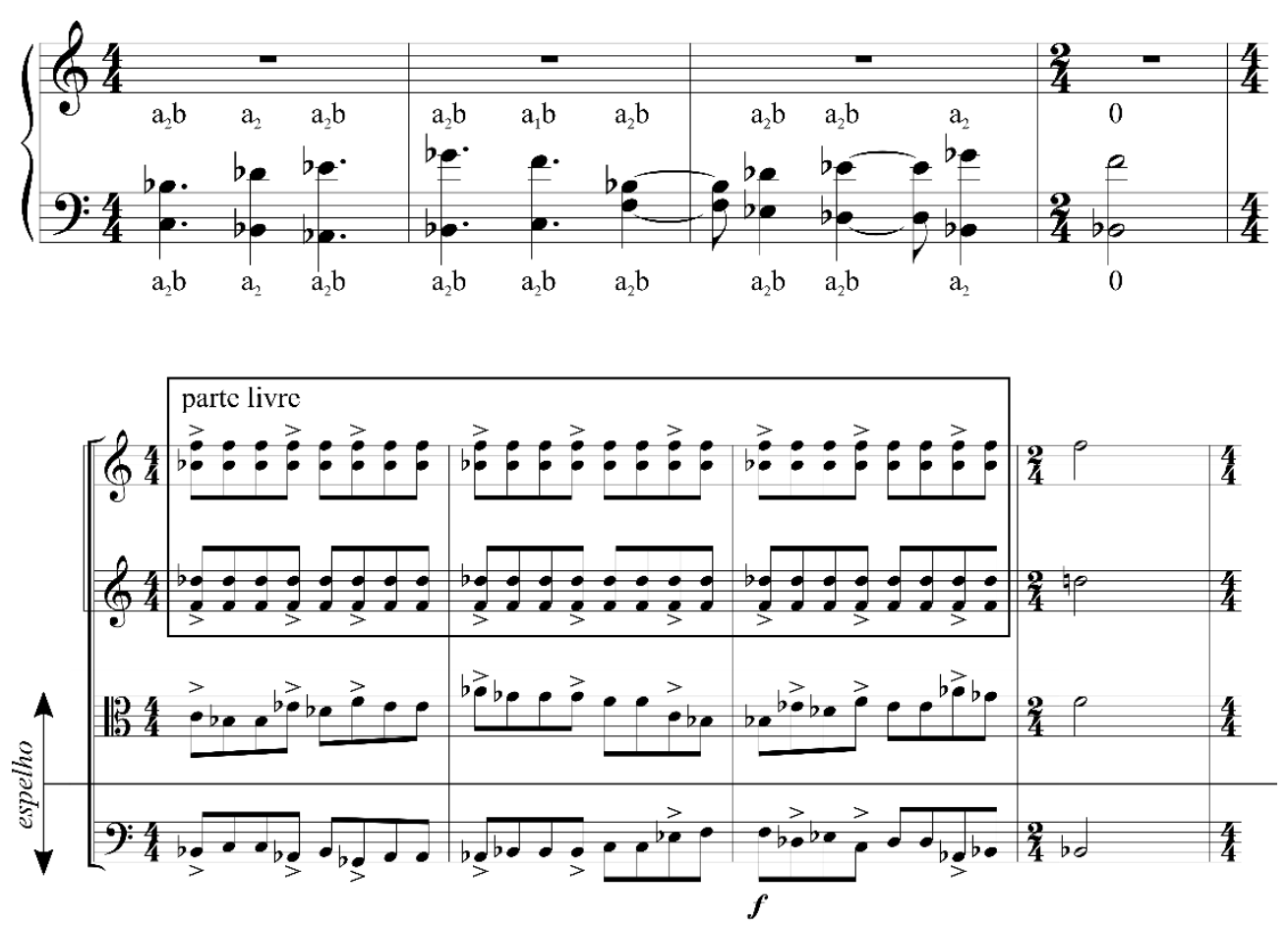

Exemplo 8: Aplicação das configurações motívicas em a2. Acima o esqueleto homofônico com configurações motívicas aplicadas e abaixo resultado da realização a duas com escrita especular entre viola e violoncelo. Para violino 1 e 2 foi composta uma parte livre, que não depende do sistema composicional. 
Na seção b1, o ritmo se torna mais flexível que nas seções anteriores. Ressaltamos aqui, também, a utilização de uma nova configuração motívica, derivada da configuração lel. Assim como acontece em $|a|$, onde o intervalo de segunda pode ocorrer como segunda maior $|a 2|$, ou segunda menor $|a 1|$ dividimos a configuração le l em le1l (terça menor) e le2l (terça maior). Apesar de utilizar praticamente as mesmas configurações motívicas básicas (com exceção de e1) do Ponteio $n^{\underline{0}}$ 21, em b1, a liberdade rítmica causa um distanciamento mais significativo se comparada às seções anteriores. Na parte superior da Exemplo 9, podemos observar o esqueleto homofônico com as configurações motívicas utilizadas e, na parte inferior, o resultado da aplicação com ritmo livre. As notas destacadas na parte do quarteto de cordas facilitam a localização das notas geradoras após a aplicação das configurações. Em suma, nesta seção, configurações motívicas e ritmos são diferentes do Ponteio $n^{\underline{0}} 21$, enquanto escrita especular e a ausência de parte livre são fatores que aproximam esta seção da escrita da obra de Guarnieri.
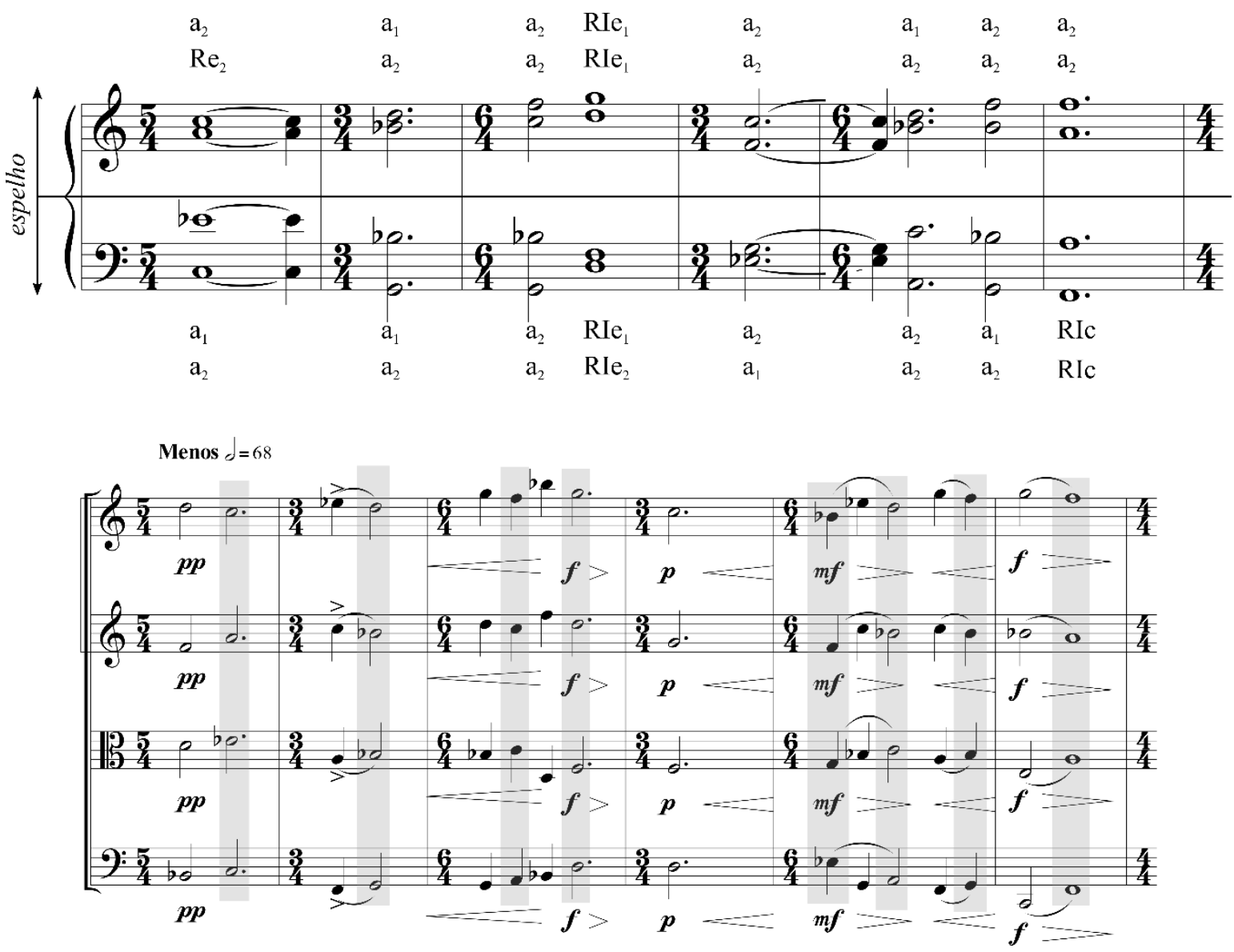

Exemplo 9: aplicação de configurações motívicas na seção b1. Acima o esqueleto homofônico e as configurações aplicadas de maneira especular entre as vozes superiores e inferiores. Abaixo, as notas do esqueleto estão destacadas, pois a liberdade de tratamento do ritmo dificulta a sua identificação 
O Exemplo 10 esclarece a maneira como utilizamos o sistema em b2. Além da liberdade rítmica, temos o deslocamento do eixo especular para uma nova posição, separando violino 1 de violino 2, viola e violoncelo. Novamente, podemos observar na parte superior do Exemplo 10 o esqueleto homofônico com as notas geradoras e as configurações motívicas e, na parte inferior, o resultado da aplicação das configurações. De maneira geral, podemos afirmar que a seção B apresenta um distanciamento, com relação ao Ponteio $n^{\underline{0}} 21$, maior do que a seção A, principalmente por causa da liberdade do tratamento do ritmo.
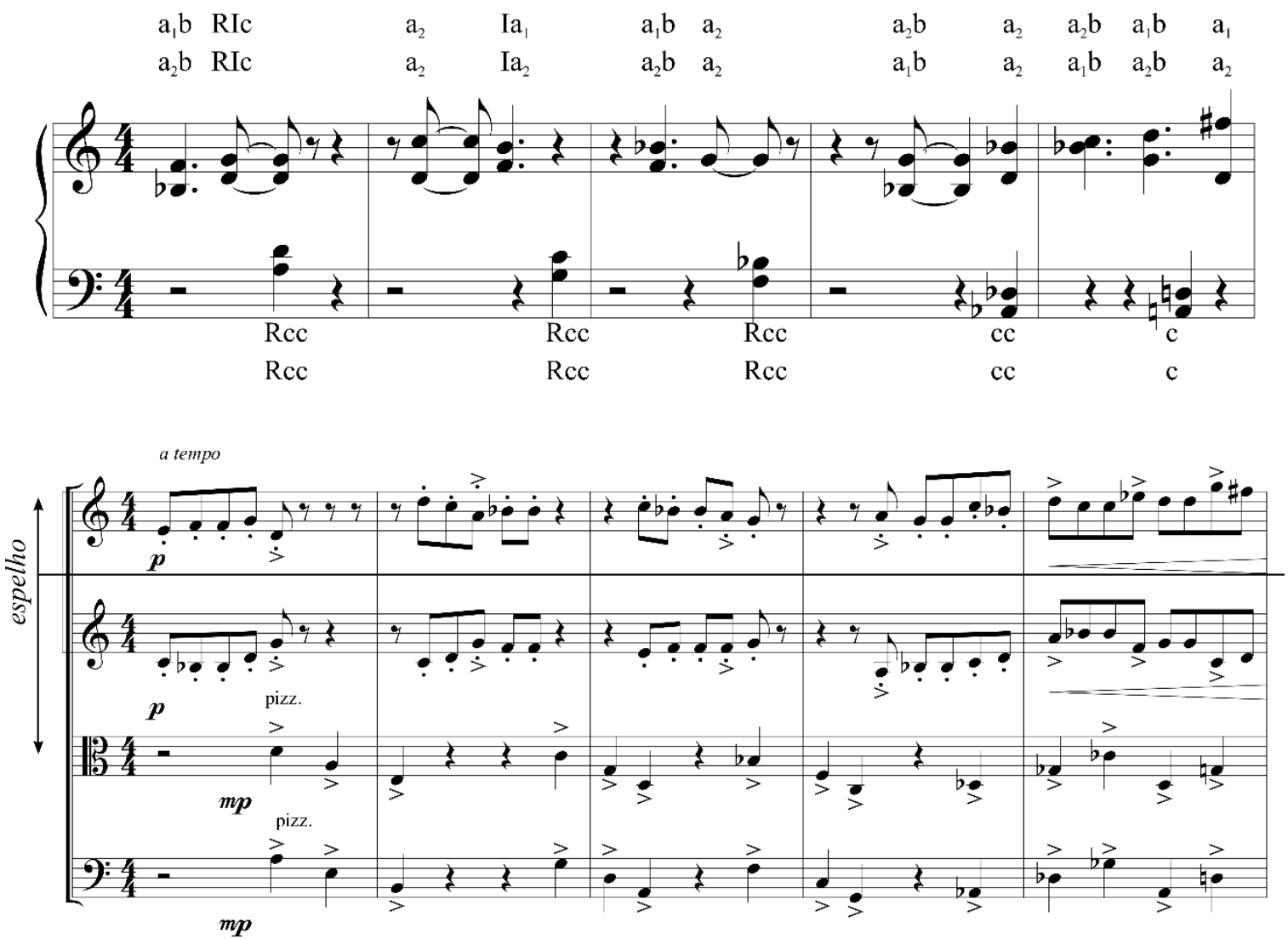

Exemplo 10: Aplicação de configurações motívicas na seção b2. Acima, o esqueleto homofônico e as configurações motívicas aplicadas a cada nota. Abaixo o resultado da aplicação das configurações de maneira especular. O eixo especular (espelho) divide violino 1 de violino 2, viola e violoncelo

A seção C apresenta uma forma de utilização mais livre do sistema composicional, com liberdade rítmica, novas configurações, utilização ou não do eixo especular e uma nova maneira de aplicar as configurações às notas geradoras. Em C, por vezes, a nota resultante da aplicação de uma configuração motívica a uma nota geradora pode surgir em outra voz. Por exemplo, a nota geradora está no violoncelo, e após a aplicação da configuração $|c|$, que resulta em uma quarta justa na direção do centro do eixo, a nota resultante é atribuída à 
viola. Nesses casos, utilizaremos a letra correspondente à configuração motívica seguida de um asterisco. Dessa maneira a nota geradora e a(s) nota(s) resultante(s) podem soar simultaneamente.

Utilizamos em C uma nova configuração motívica básica denominada $|\mathrm{f}|$, que é dividida em If1 | e |f2 | representando os intervalos de sexta menor e sexta maior respectivamente. Em toda a peça, somente encontramos a configuração $|\mathrm{f}|$ na forma de $\left|f^{*}\right|$, ou seja, o resultado da aplicação de $|f|$ sempre resultará em uma nota atribuída a outra voz.

Quando não há a escrita especular, utilizaremos o intervalo da configuração motívica em qualquer direção, como veremos no Exemplo 11, que corresponde à utilização do sistema composicional nos primeiros compassos de c1. Nesse trecho, utilizamos uma melodia livre de configurações motívicas que foi atribuída ao violino 1 . As notas geradoras da voz inferior foram atribuídas à viola e as notas resultantes da dupla aplicação da configuração motívica $\left|c^{*}\right|$ (quarta justa acima e abaixo) foram atribuídas ao segundo violino e ao violoncelo.
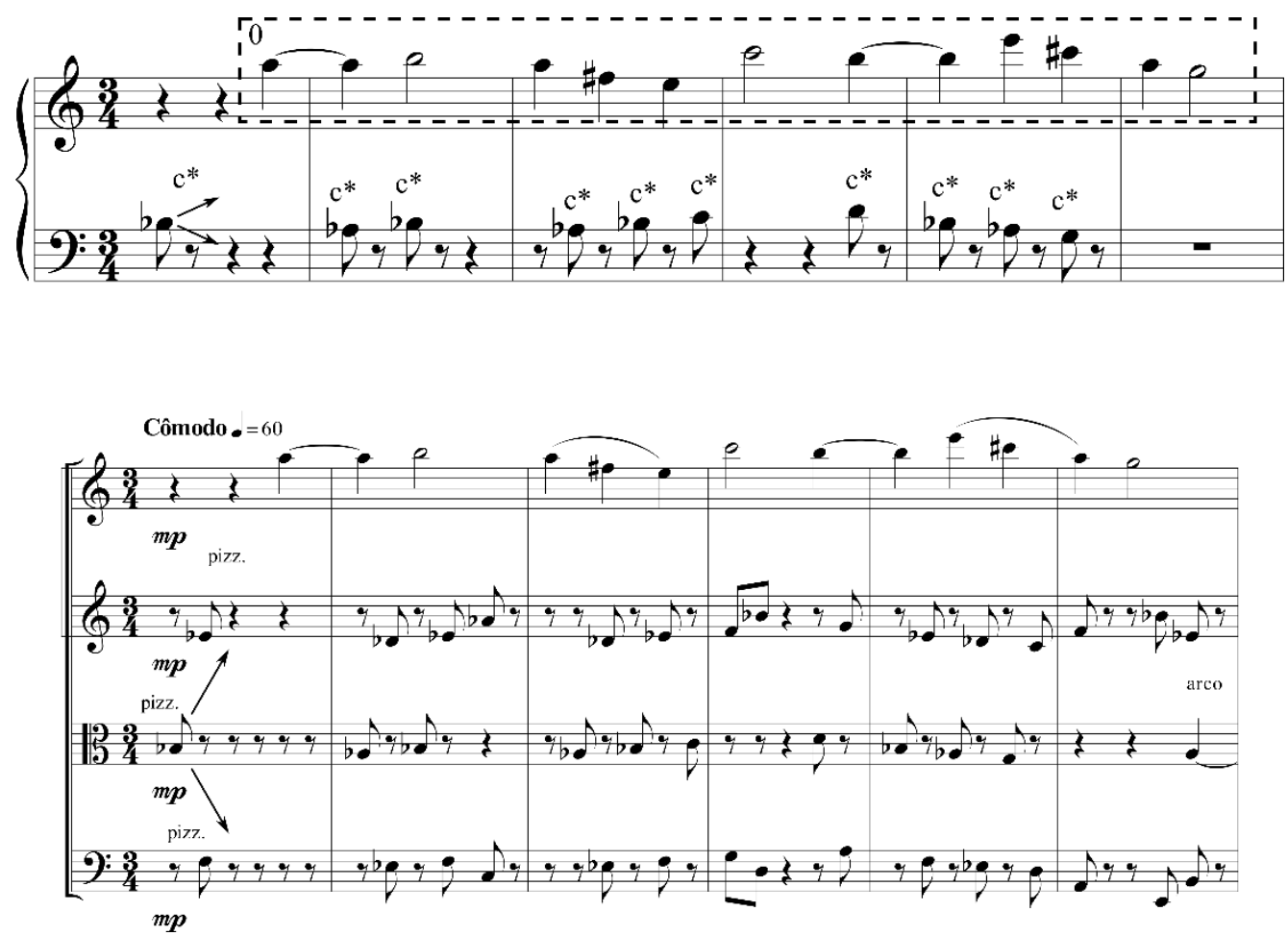

Exemplo 11: Utilização das configurações motívicas em c1. Acima, o esqueleto, com uma parte sem configurações motívicas aplicadas identificada com o retângulo pontilhado e um " 0 ", e uma parte com a configuração c* atribuída a cada nota. Abaixo, a parte de viola contém as notas do esqueleto e a aplicação da configuração c* de maneira especular pode ser observada no violoncelo e violino 2

De maneira similar, ainda na seção $\mathrm{c} 1$, temos uma melodia formada por notas geradoras atribuídas ao violoncelo e a aplicação das configurações $\left|c^{*}\right|$ 
gerando as notas dos violinos 1 e 2 e $\left|\mathrm{f} 1^{*}\right|$ gerando as notas da viola (Exemplo 19). Utilizamos também de forma mais livre a aplicação de $\left|c^{*}\right|$, que nesse trecho resultou em uma sequência de várias quartas justas seguidas, sempre partindo da nota geradora, como pode ser observado na parte de violino 2. Essa é a seção de Quadrilha que mais se distancia do Ponteio $n^{\underline{0}} 21$. Ela não utiliza a escrita especular, tem ritmo livre e utiliza uma configuração motívica básica que não está presente no Ponteio $n^{0}$ 21. Além disso, a inclusão de parte livre (violino 1) é também outro fator de diferenciação com relação ao ponteio de Guarnieri.
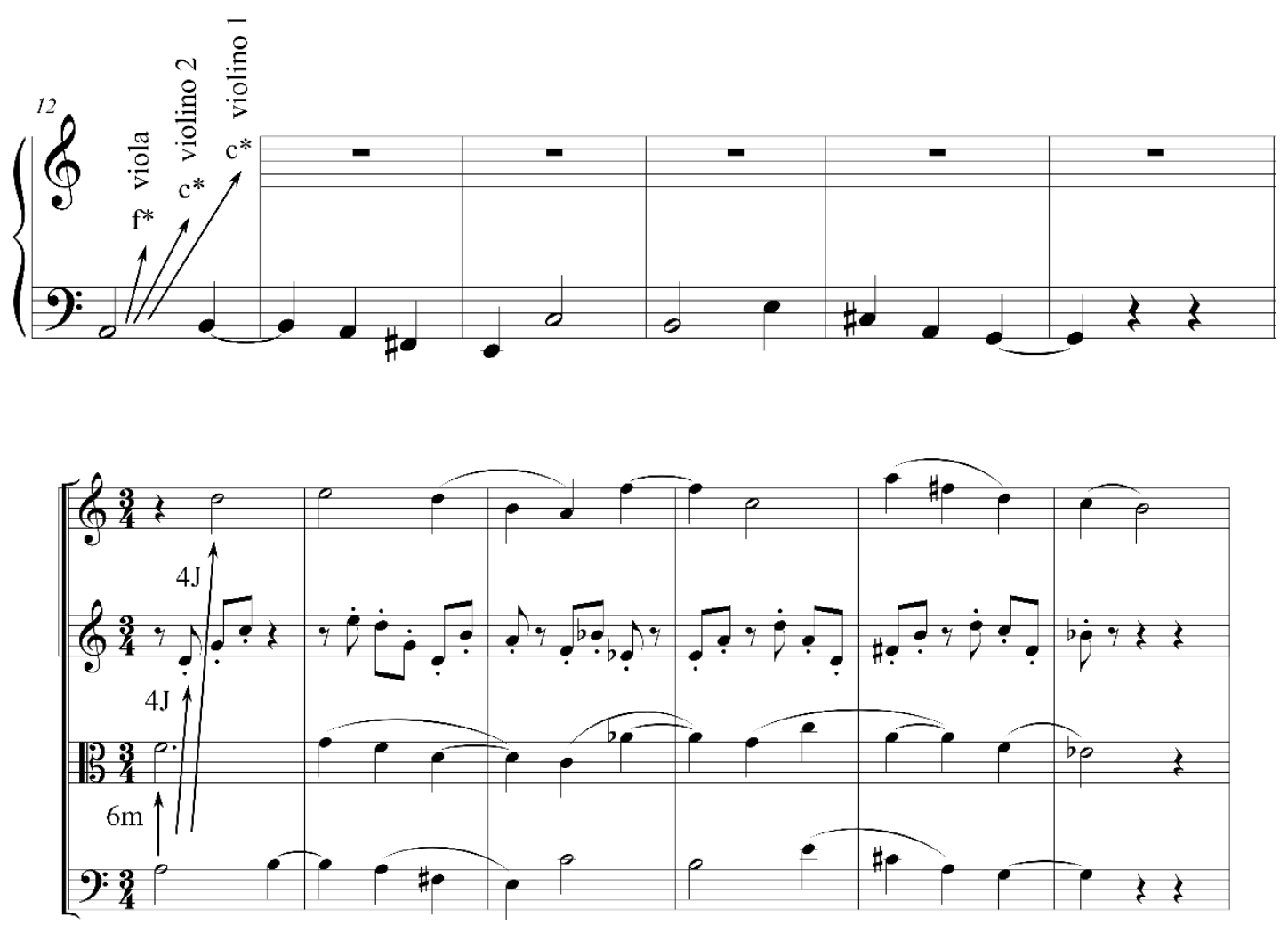

Exemplo 12: utilização das configurações motívicas em c1. O exemplo mostra a aplicação dos motivos $\mathrm{c}^{*}$ e $\mathrm{f}^{*}$ a partir do violoncelo para viola, e violinos de maneira livre com relação ao ritmo. No segundo violino podemos observar que a configuração $c^{*}$ é aplicada diversas vezes à própria parte resultando em quartas justas seguidas

Na seção c2 o eixo especular e as configurações motívicas do Ponteio $n^{\underline{o}} 21$ retornam como elementos importantes. No Exemplo 13 podemos observar o eixo especular dividindo violino 1 de violino 2, viola e violoncelo. Entre violinos 1 e 2 foram utilizadas configurações semelhantes assim como entre viola e violoncelo.

No início do quarto compasso de c2, ocorre uma modificação do eixo especular para uma posição central, dividindo violino 1 e 2 de viola e violoncelo. Além disso, é utilizada a mesma configuração motívica para todas as vozes. $\mathrm{O}$ eixo especular retorna dois tempos depois à posição anterior. Essa mudança foi utilizada como elemento articulador nos finais de frase de c2. Nessa seção, o ritmo é utilizado livremente e não há inclusão de parte livre. 

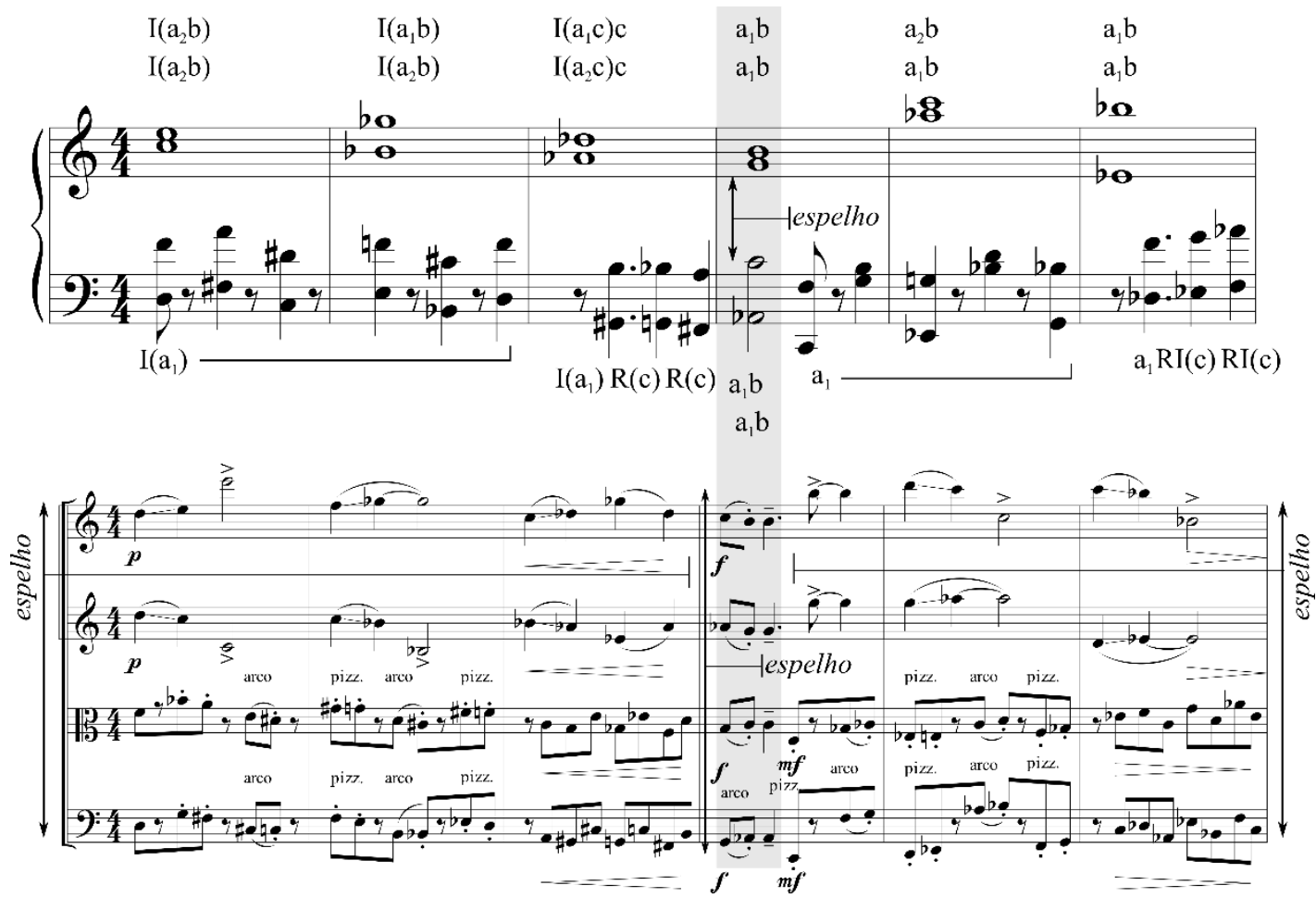

Exemplo 13: Utilização das configurações motívicas em c2, com o eixo especular que inicialmente está localizado entre violino 1 e os demais instrumentos e no quarto compasso é momentaneamente transferido para o centro (parte destacada no exemplo)

Na seção c3, mostrada no Exemplo 14, temos as notas geradoras atribuídas ao violoncelo, cuja parte funciona como eixo para aplicação das configurações, $\left|c^{*}\right|$ para viola e violino 2, e $\left|c c^{*}\right|$ para violino 1. A configuração $\left|c c^{*}\right|$, diferentemente de $|c c|$, que corresponde a duas quartas seguidas na direção do centro, significa a transposição uma sétima menor acima (duas quartas justas). Esta seção apresenta configurações motívicas novas, ritmo diferenciado em relação ao Ponteio $n^{\underline{0}}$ 21, e escrita não especular, porém não apresenta parte livre. 

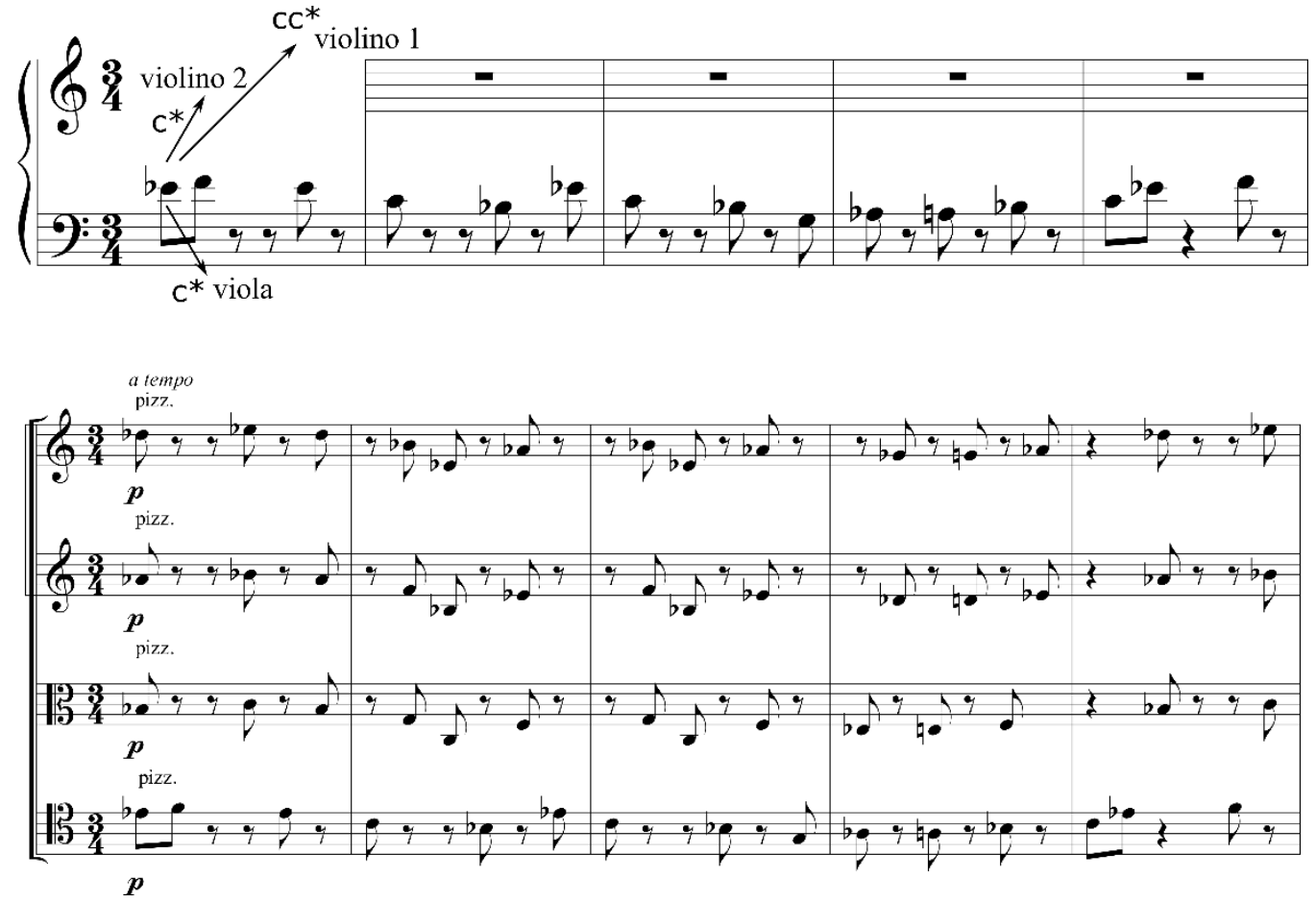

Exemplo 14: Utilização do sistema composicional em c3, com as notas geradoras e configurações motívicas aplicadas. As notas geradoras estão atribuídas ao violoncelo e o resultado das configurações está projetado na viola e violinos
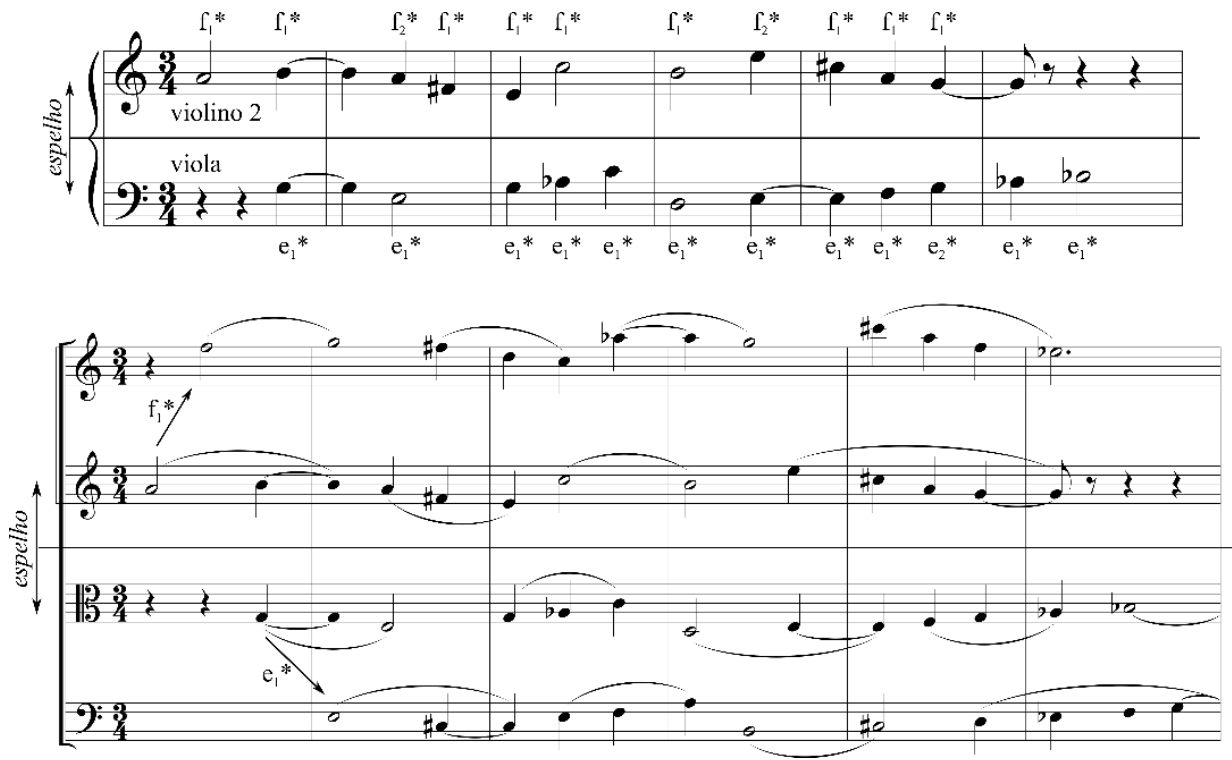

Exemplo 15: utilização do sistema composicional em c4, com duas linhas de notas geradoras e as configurações motívicas aplicadas a cada nota. Abaixo, as linhas com notas geradoras estão atribuídas a viola e segundo violino, e as notas consequentes da aplicação das configurações estão projetadas em violoncelo e primeiro violino 

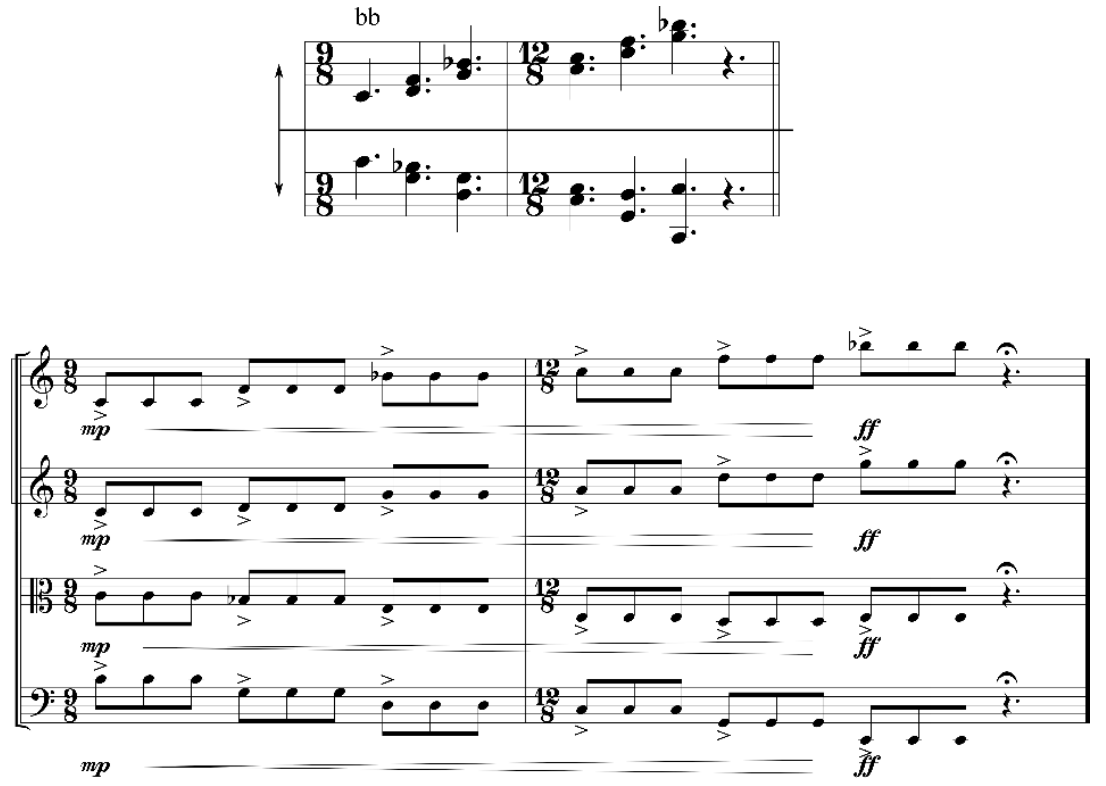

Exemplo 16: Últimos dois compassos da peça e da seção a3. Acima, o esqueleto homofônico com as notas geradoras, às quais foi atribuída a configuração motívica $\mid$ bb $\mid$. Abaixo, o resultado da aplicação das configurações

\section{5 - Considerações Finais}

Como pudemos observar no presente trabalho, a Modelagem Sistêmica, enquanto metodologia analítico-composicional, foi capaz de produzir um aparato composicional eficiente, utilizado para a composição de Quadrilha, ao mesmo tempo que resultou em uma análise profunda do Ponteio $n^{\underline{0}} 21$ de Camargo Guarnieri.

Com relação ao aspecto analítico, a MS mostrou flexibilidade, oferecendo a possibilidade de uma abordagem analítica criada especificamente para $\mathrm{o}$ Ponteio $n^{\underline{0}}$ 21. A metodologia de redução utilizada nos possibilitou observar comportamentos internos de parâmetros texturais e melódicos que, a princípio, não estavam aparentes na superfície musical. A MS apresenta como característica, assim como a Teoria Geral dos Sistemas, a multidisciplinaridade. Para cada obra a ser modelada devem ser eleitas as ferramentas analíticas, oriundas de diversos campos teóricos, que melhor se adequem aos objetivos do modelador. Deve ser levado em consideração que a fase de análise desta metodologia, quando aplicada a fins composicionais, envolve uma postura pragmática, ou seja, as decisões analíticas estão submetidas mais aos objetivos composicionais do que a uma necessidade de propor uma solução reveladora da poética do compositor.

Com relação ao lugar ocupado pela MS dentro da utilização da intertextualidade como ferramenta composicional, acreditamos que ela se 
constitui como uma abordagem flexível e ao mesmo temo precisa do intertexto, pois possibilita que a proximidade entre a nova obra e a obra modelada seja controlada de maneira objetiva a partir da escolha de parâmetros e do tratamento desses parâmetros. O caso particular da modelagem do Ponteio $n^{\underline{0}} 21$ se mostra especialmente relevante, com relação a esse aspecto. Aqui, a utilização de um quadro de níveis de influência do intertexto na nova obra, por meio de um protocolo quantitativo binário nos possibilitou uma escolha racional do nível de influência da obra original na nova obra.

\section{REFERÊNCIAS}

1. Verhaalen, Marion. 2001. Camargo Guarnieri: Expressões de uma Vida. São Paulo: EDUSP.

2. Wagner, Joseph. 1959. Orchestration: a Practical Handbook. New York: McGrawHill. 


\section{ANEXO: Configurações Motívicas do Ponteio $n^{o} \mathbf{2 1}$ de Guarnieri}
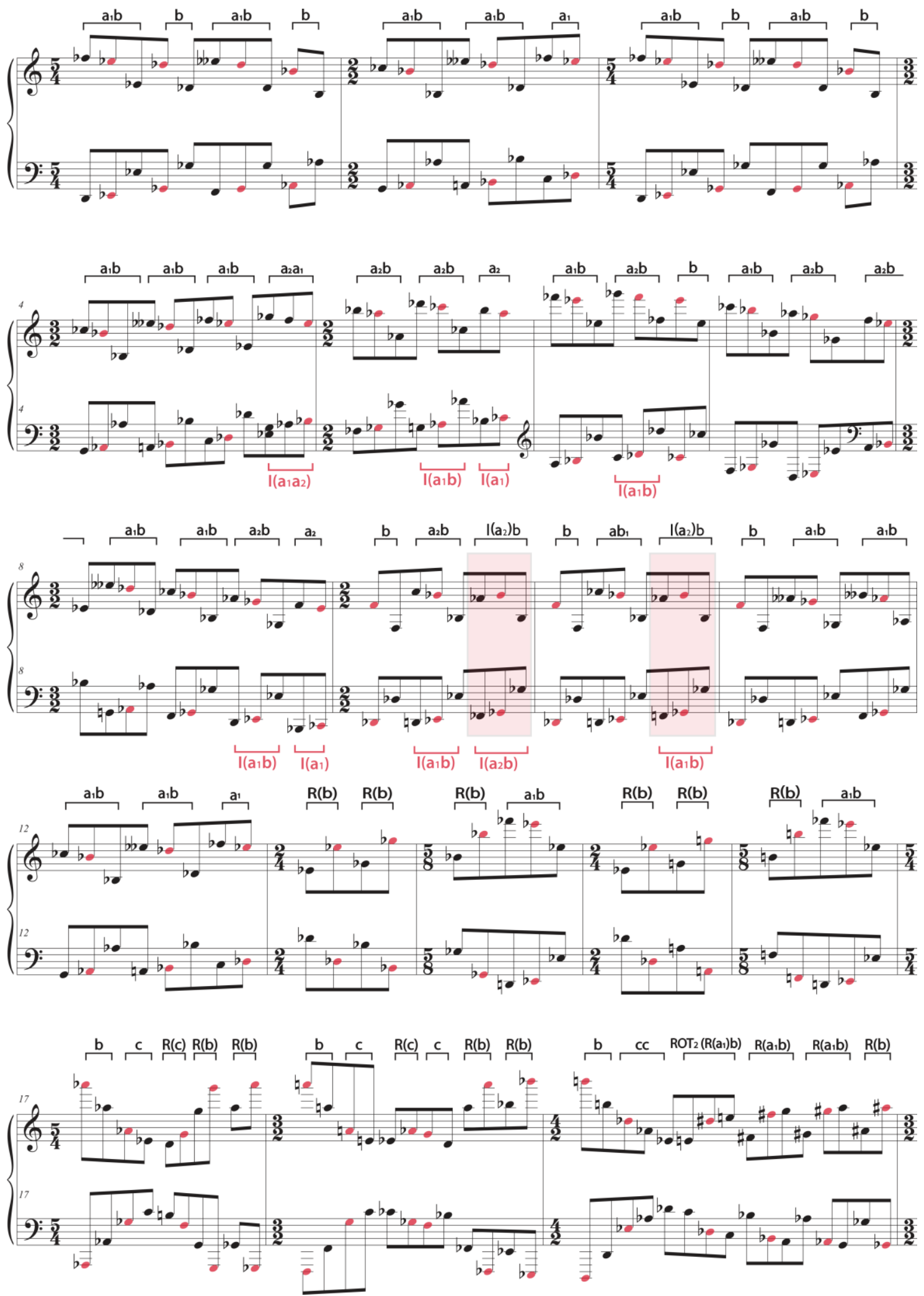

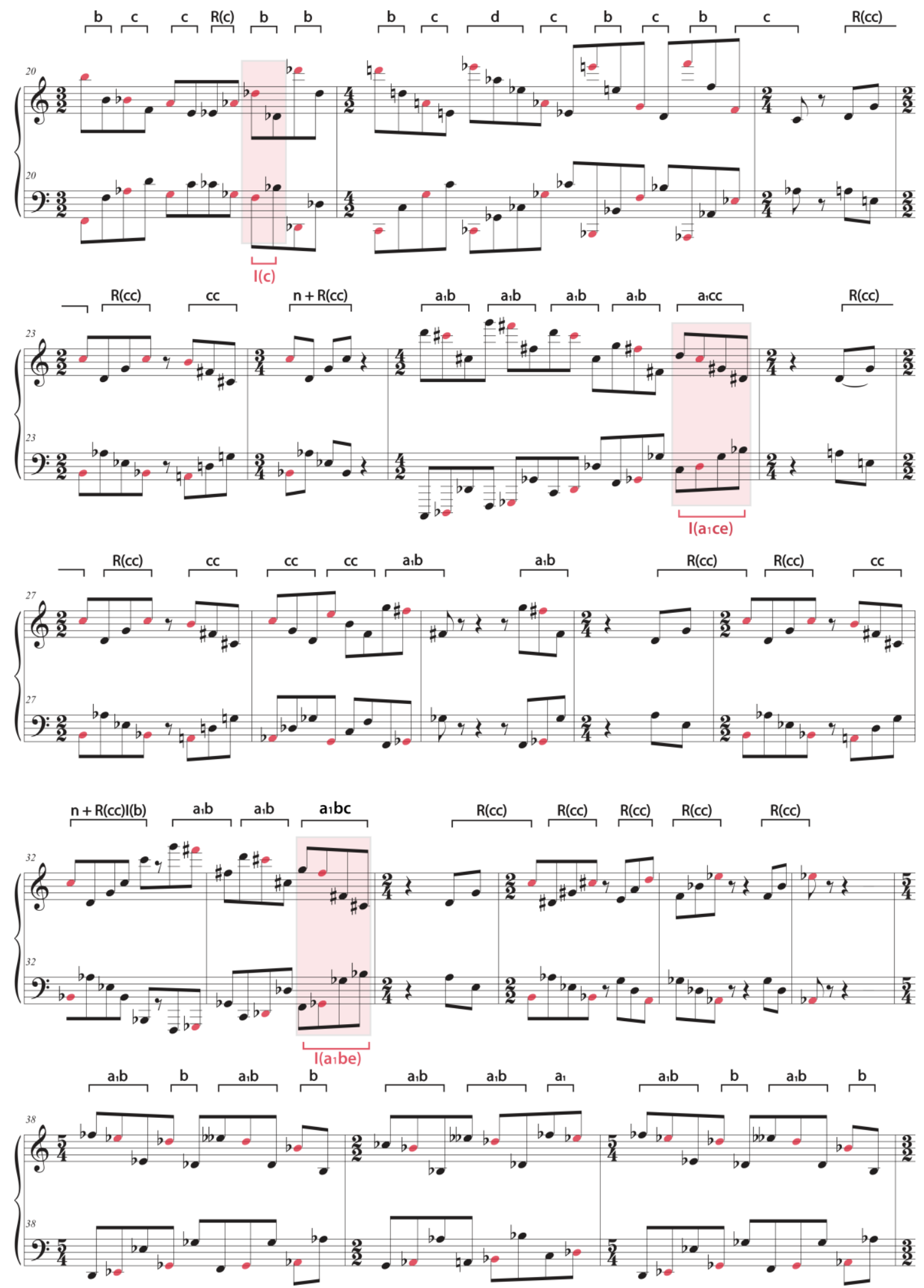

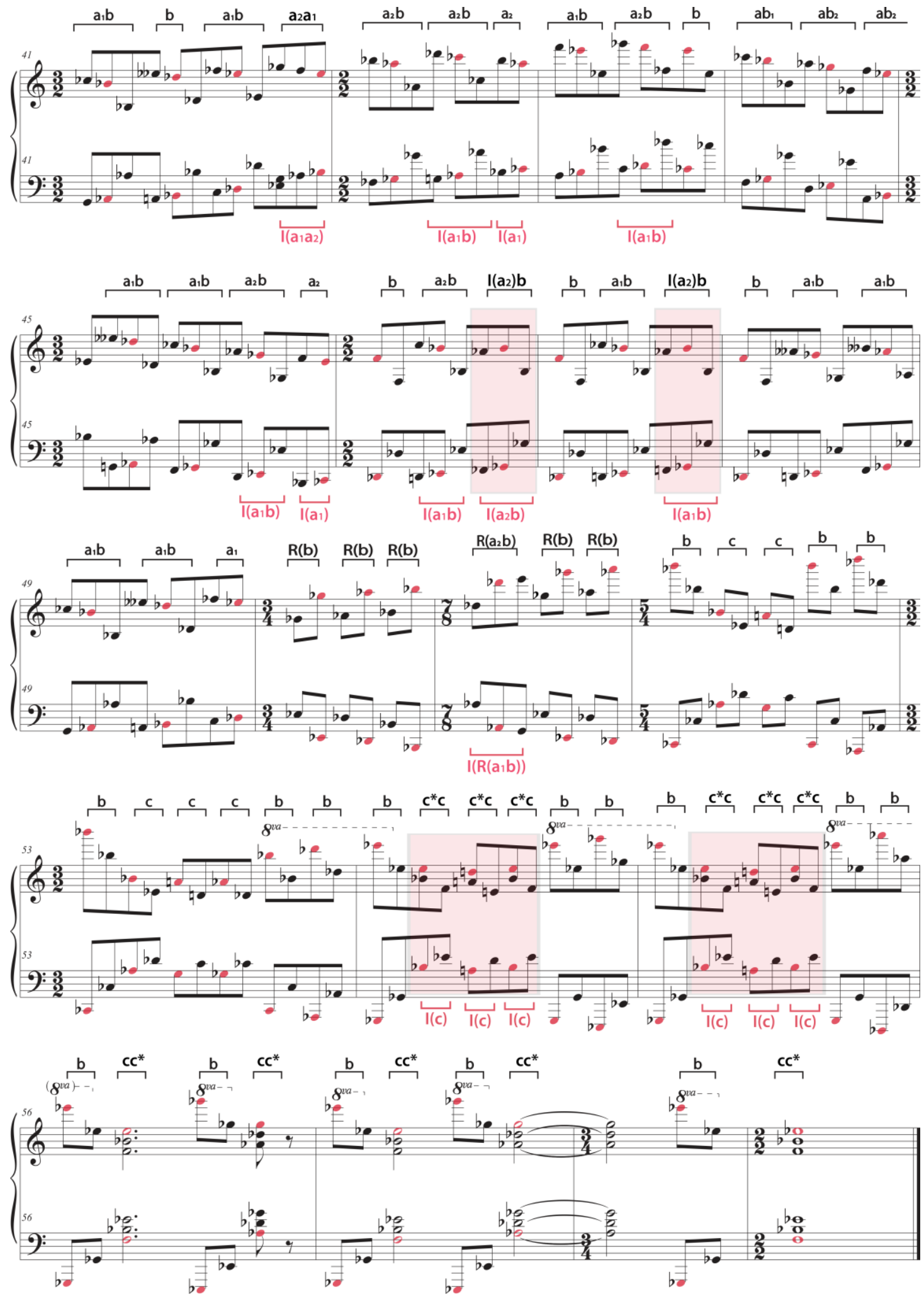